\title{
Supramolecular interactions between polylactide and model cyclosiloxanes with hydrogen bonding-capable functional groups
}

\author{
A. S. Herc ${ }^{1}$, M. Włodarska ${ }^{2}$, M. Nowacka ${ }^{1}, J$. Bojda $^{1}$, W. Szymański ${ }^{3}$, A. Kowalewska ${ }^{1 *}$ \\ ${ }^{1}$ Centre of Molecular and Macromolecular Studies, Polish Academy of Sciences, Sienkiewicza 112, 90-363 Łódź, Poland \\ ${ }^{2}$ Institute of Physics, Lodz University of Technology, Wólczańska 219, 90-924 Łódź, Poland \\ ${ }^{3}$ Institute of Materials Science and Engineering, Lodz University of Technology, Stefanowskiego 1/15, 90-924 Łódź, \\ Poland
}

Received 16 May 2019; accepted in revised form 3 August 2019

\begin{abstract}
Interactions between polylactide matrix and additives bearing - $\mathrm{COOH}$ and - $\mathrm{OH}$ groups were studied for compositions of polylactide (PLA) and functionalized cyclotetrasiloxanes ( $\mathrm{CX}-\mathrm{R}, \mathrm{R}=\mathrm{OH}, \mathrm{COOH}, \mathrm{COOMe}$ ). Inherent conformational flexibility of cyclotetrasiloxane rings enabled evaluation of supramolecular phenomena between hydrogen bondingcapable functional groups and the polylactide backbone, as well as their role in polymer crystallization. The modification of PLA with CX-R was clearly reflected in the polymer dielectric response, unobscured by interfacial polarization effects frequently observed for other additives. New relaxation processes appeared next to the strong $\alpha$-relaxation characteristic of the PLA matrix. Addition of CX-R influenced thermally induced crystallization of amorphous matrix as well as isothermal crystallization from melt. Development of crystals with $10_{3}$ helical chain conformation was accelerated at relatively low temperatures in the presence of $\mathrm{CX}-\mathrm{OH}$ with hydrogen bond donating hydroxyl groups. A specific phase separation that hindered mobility of polymer chains was observed in samples prepared with $\mathrm{CX}-\mathrm{COOH}$ of strong hydrogen bond donor/acceptor ability. The presented results may be used as a reference for other systems with nanoadditives such as carbon nanotubes (CNT), graphene oxide (GO) or carbon quantum dots, in which interactions between $-\mathrm{COOH} /-\mathrm{OH}$ groups and the polymer matrix play an important role.
\end{abstract}

Keywords: material testing, biodegradable polymers, dielectric relaxation, supramolecular interactions, cyclosiloxanes

\section{Introduction}

Polylactide/poly(lactic acid) (PLA) are well-known biocompatible and biodegradable semicrystalline polymers, that require modification in order to improve their mechanical properties, thermal characteristics and crystallization rate [1-4]. PLA crystallizes typically with a characteristic distorted $10_{3}$ helical chain conformation (orthorhombic $\alpha$-form and a less ordered $\alpha^{\prime}$-form) $[5,6]$. Nucleation of PLA crystals is slow, especially if the macromolecules contain a share of isomeric D-lactide units that disturb formation of well-ordered sequences along the chain axis $[7,8]$. The induction period before the crystal growth can be reduced and the crystallization kinetics can be improved in the presence of hybrid components that enhance nucleation density, or plasticisers that facilitate chain mobility [8]. The aspect ratio of the hybrid additives and contact area at the interface with polymer matrix is of exceptional significance for the process of crystallization and consequently for thermal, mechanical and gas barrier properties of PLA as well as their biodegradability [3]. Compounds capable of strong supramolecular interactions can change vastly the process of crystallization

$\overline{{ }^{*} \text { Corresponding author, e-mail: anko@cbmm.lodz.pl }}$ (C) BME-PT 
of PLA. Graphene, carbon nanotubes, carbon nanofibers and carbon quantum dots as low-dimensional carbonaceous nanofillers effectively enhance crystallization of the polymer [9-13]. Interesting results were also obtained with low molecular weight species that crystallize at $T>T_{\mathrm{c}}$ of PLA and are capable of the formation of hydrogen bonds with the polyester backbone. Such compounds (e.g. sorbitol [14], hydrazide $[15,16]$ and amide [17-19] nucleators) provide nucleation sites in the polymer melt for epitaxial crystallization of PLA.

Broadband dielectric spectroscopy (BDS) studies provided a vast amount of information about the molecular dynamics of PLA and differences in the relaxation processes caused by additives. Local fluctuations below the glass transition temperature $\left(T_{\mathrm{g}}\right)$ of neat PLA are reflected in a $\beta$ dielectric relaxation whereas segmental dynamics ( $\alpha$-relaxation) is increased at $T>T_{\mathrm{g}}$ [20]. Crystallization of PLA was also analysed in details with BDS [21-23]. The relaxation behaviour of the nanocomposites was found to be much more complex than that of neat PLA. For example, addition of organically modified Ni/Al layered double hydroxides resulted in the presence of three additional dielectric active processes, including relaxation of surfactants and water molecules within the layers of inorganic components and interfacial polarization effects at $T>T_{\mathrm{g}}$ [24]. The Maxwell/ Wagner/Sillars (MWS) polarization was also observed for PLA nancomposites with montmorillonite [25], graphene oxide (GO) [26] and carboxylated carbon nanotubes (CNT) [27]. The strong effect often overshadows more subtle phenomena connected with the presence of functional groups $(-\mathrm{COOH}$, $-\mathrm{OH})$ on the surface of carbon quantum dots, CNT and GO layers. As a consequence the role of those functional groups in the organization of the polymer matrix, due to their capability of hydrogen bonding to PLA, could not be estimated accurately.

We have found that the isolated effect of supramolecular interactions between PLA chains and carboxyl and hydroxyl groups can be evaluated by employing functionalized cyclotetrasiloxane additives $(\mathrm{CX}-\mathrm{R})$ (Figure 1). Species bearing multiple carbonyl/carboxyl or hydroxyl groups were obtained by thiol-ene addition of a range of thiols to 1,3,5,7-tetravinyl1,3,5,7-tetramethyl-cyclotetrasiloxanes. Owing to the substantial flexibility of siloxane bonds and side alkyl chains, the interactions of PLA with CX-R do

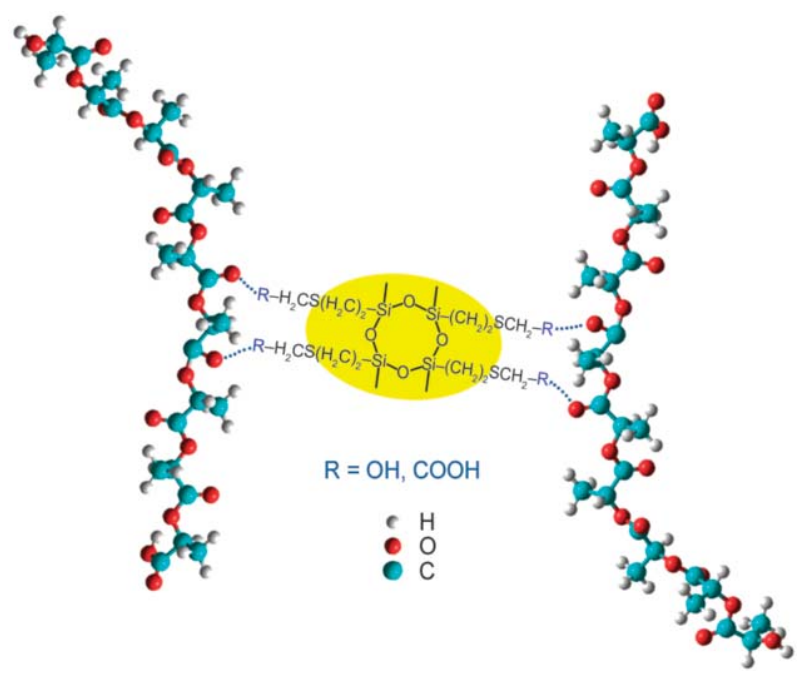

Figure 1. Supramolecular interactions between PLA chains and $\mathrm{CX}-\mathrm{OH}$ or $\mathrm{CX}-\mathrm{COOH}$.

not involve manifestation of any defined interphase effects.

A detailed BDS analysis of interactions between PLA and CX-R is provided. Thermal characteristics and the dynamic behaviour of PLA/CX nanocomposites were also studied using calorimetric (differential scanning calorimetry, DSC) as well as spectroscopic (Fourier-transform infrared spectroscopy, FTIR) techniques. We have found that the specific ability of functional groups to take part in supramolecular interactions with polylactide chains as hydrogen bond donors/acceptors alters strongly the polymer dielectric response. It can be also related to the observed cold crystallization, which is quite interesting taking into account the very low aspect ratio of $\mathrm{CX}-\mathrm{R}$ additives. The type and amount of $\mathrm{CX}-\mathrm{R}$ influenced the crystallization of PLA and the rate of $10_{3}$ helical structures formation. The results, combined with no detrimental effect of CX-R on the thermal stability of PLA, and a scarce or small decrease of the polymer light transmittance at low additive loading, make the functionalized cyclosiloxanes interesting models for studies on the impact of hydrogen bonding on PLA matrix. Moreover, there is also a quite important practical aspect of modification of PLA by addition of CX-R. Polylactide is commonly used as a thermoplastic material for fused deposition modelling (FDM) in 3D printing of e.g. scaffolds for regenerative medicine or artificial tissues [28, 29]. The process typically involves extrusion of melted material and then rapid cooling which makes the material brittle. That is why thermal annealing at temperatures corresponding to the cold crystallization 
process has to be applied to even out the areas of high and low stress and increase the strength and stiffness of 3D printed parts. Modification of the properties of FDM printed PLA objects by addition of inorganic additives and macromolecules has been described [30,31]. It can be also expected that shifting cold crystallization of PLA towards lower temperatures in the presence of CX-R can be beneficial in terms of improved physical properties and dimensional stability of the printed objects as well as a lower energy use.

\section{Experimental}

\subsection{Materials}

CX-R were prepared by thiol-ene addition of mercapto-compounds: $\mathrm{CX}-\mathrm{COOH}$ - thioglycolic acid (98\%, Sigma-Aldrich, United States), CX-COOMe - methyl thioglycolate (95\%, Acros Organics, Belgium), CX-OH - 2-mercaptoethanol (99\%, Sigma-Aldrich, United States) and CX-(OH $)_{2}-1$-thioglycerol $(99 \%$, Sigma-Aldrich, United States) to vinyl groups of 1,3,5,7-tetravinyl-1,3,5,7-tetramethylcyclotetrasiloxanes (CX-Vi) $(97 \%$, a mixture of isomers; ABCR $\mathrm{GmbH}$, Germany) (Figure 2). The synthesis was carried out following earlier reported procedures $[32,33]$ using 2,2-dimethoxy-2-phenylacetophenone (DMPA) ( $99 \%$, Acros Organics, Belgium) as the photoinitiator. Solvents used for the experiments were purified following literature procedures [34].

In general a thiol derivative $(29.17 \mathrm{mmol})$ and $\mathrm{CX}-\mathrm{Vi}$ (6.65 mmol) dissolved in dry tetrahydrofuran (THF) $(210 \mathrm{ml})$ were placed in a quartz vessel. DMPA $(0.53 \mathrm{mmol})$ was added with stirring to the solution of reagents. The mixture was irradiated for $15 \mathrm{~min}$ with UV light $(\lambda=356 \mathrm{~nm})$. Products were purified by silica gel column chromatography, using ethyl acetate as the mobile phase for $\mathrm{CX}-\mathrm{COOH}$, $\mathrm{CX}-\mathrm{COOMe}$ and $\mathrm{CX}-\mathrm{OH}$, or a mixture of ethyl acetate and $\mathrm{MeOH}$ for $\mathrm{CX}-(\mathrm{OH})_{2}$. Fractions containing
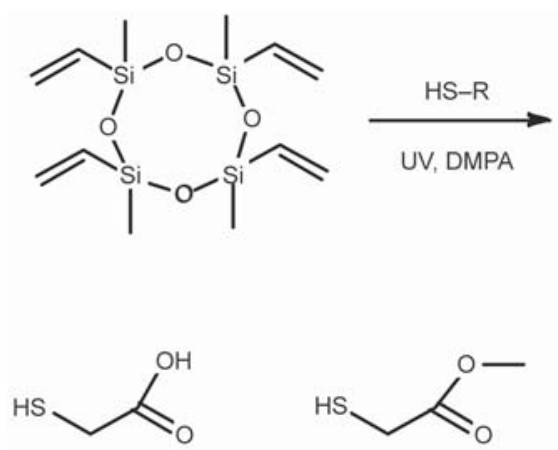

the desired product were combined and dried over $\mathrm{MgSO}_{4}$. After filtration, volatiles were removed from the solution and the residue was dried to constant weight under high vacuum. Liquid state ${ }^{1} \mathrm{H},{ }^{13} \mathrm{C}$ and ${ }^{29} \mathrm{Si}$ NMR spectra of all the obtained $\mathrm{CX}-\mathrm{R}$ were recorded in THF-d8 as a solvent on a Bruker DRX-500 MHz spectrometer (Billerica, Massachusetts, United States).

Polylactide (PLA), commercially available NW 2003D grade from NatureWorks LLC (Minnetonka, MN, United States) used for the study contained 3.2\% molar content of D-lactide units $\left(M_{\mathrm{w}}=196 \mathrm{~kg} \cdot \mathrm{mol}^{-1}\right.$ and dispersity $\left.M_{\mathrm{w}} / M_{\mathrm{n}}=1.7\right)$. It was purified for the experiments by precipitation using $\mathrm{CH}_{2} \mathrm{Cl}_{2} / \mathrm{MeOH}$ as the solvent/nonsolvent system and carefully dried under high vacuum to constant weight.

$\mathrm{PLA} / \mathrm{CX}-\mathrm{R}$ nanocomposites containing various amounts of $\mathrm{CX}-\mathrm{R}\left(\mathrm{R}=\mathrm{COOH}, \mathrm{COOMe}, \mathrm{OH},(\mathrm{OH})_{2}\right.$ and $\mathrm{Vi}$ ) were prepared by mixing solutions of PLA in $\mathrm{CH}_{2} \mathrm{Cl}_{2}(c=11 \mathrm{wt} \%)$ with a given amount of $\mathrm{CX}-\mathrm{R}$ dissolved in THF [or $\mathrm{MeOH}$ in the case of $\mathrm{CX}-(\mathrm{OH})_{2}$ due to its insolubility in THF] ( $c=15 \mathrm{wt} \%)$ for $2 \mathrm{~h}$ under magnetic stirring. On addition of $\mathrm{CX}-\mathrm{COOH}$, $\mathrm{CX}-\mathrm{OH}$ and $\mathrm{CX}-(\mathrm{OH})_{2}$ the mixtures became cloudy in a short time (less than 3 minutes) and remained turbid on prolonged stirring. The effect was not observed for $\mathrm{CX}-\mathrm{COOMe}$ and $\mathrm{CX}-\mathrm{Vi}$. No increase of viscosity was involved but the turbidity disappeared on sample dilution. The prepared mixtures were then poured into Petri dishes and left for free solvent evaporation. Solid products were dried for $24 \mathrm{~h}$ at $80^{\circ} \mathrm{C}$ under high vacuum (0.01 Torr). For further studies, thin $(0.5 \mathrm{~mm})$ films were compression molded at $190^{\circ} \mathrm{C}$ and rapidly quenched at $0^{\circ} \mathrm{C}$.

\subsection{Analytic methods}

Native PLA NW 2003D and the prepared compositions PLA/CX-R were studied in bulk using a DSC 2920 Modulated thermal analysis system (TA<smiles>[R]SCC[Si]1(C)O[Si](C)(CCS[R])O[Si](C)(CCS[R])O[Si](C)(CCS[R])O1</smiles><smiles>OCCS</smiles><smiles>OCC(O)CS</smiles>

Figure 2. Synthesis and structure of the functionalized CX-R used as additives to PLA. 
Instruments; New Castle, DE, United States). Thermograms were taken for samples (sealed in aluminium pans) heated as described in the text. Thermogravimetric analyses were carried out using a Hi-Res TGA 2950 Thermogravimetric Analyzer (TA Instruments; New Castle, DE, United States) under $\mathrm{N}_{2}$ atmosphere (heating rate $10^{\circ} \mathrm{C} \cdot \mathrm{min}^{-1}$, resolution 3 , sensitivity 3).

Broadband dielectric spectroscopy was performed on samples of initially amorphous polymer matrix in the form of $0.5 \mathrm{~mm}$ films placed between brass electrodes in sandwich-type cells. The real and imaginary components of complex permittivity were recorded in a broad frequency range $\left(10^{-1} \div 10^{6} \mathrm{~Hz}\right)$ using a Novocontrol system comprising an Alpha high-resolution dielectric analyser and a Quatro cryosystem (Novocontrol Technologies; Montabaur, Germany). The dielectric profiles were acquired during heating in the temperature range of $20 \div 150{ }^{\circ} \mathrm{C}$. Each frequency sweep took place after temperature stabilization with $0.1^{\circ} \mathrm{C}$ accuracy.

Morphological investigations and the distribution of silicon atoms in the studied samples were carried out using a scanning electron microscope (SEM) with energy-dispersive X-ray spectroscopy (EDS) microanalyser (Jeol JSM-6010LA; Tokyo, Japan) operating in the high vacuum mode and at an accelerating voltage $10 \mathrm{kV}$. The cryo-fractured surfaces were coated with carbon by sputtering in a compact rotarypumped coating system, Q150R ES (Quorum Technologies; Lewes, Great Britain).

Direct light transmittance through $0.5 \mathrm{~mm}$ thick samples of native PLA and the nanocomposites was measured at RT using a UV-VIS SPECORD S 600 diode array spectrophotometer (Analytik Jena AG; Jena, Germany) in the wavelength range from 200 to $1000 \mathrm{~nm}(0.5 \mathrm{~nm}$ resolution $)$ with reference to air. Data were averaged for at least 3 runs.

FTIR spectra were recorded [Nicolet 380 FTIR spectrometer (Thermo Fisher Scientific; Waltham, Massachusetts, United States), equipped with a heated cell and Harrick ATC/low voltage controller (Harrick Scientific Products: Inc. Pleasantville, New York, United States)] for thin films cast on $\mathrm{KBr}$ crystal windows from $0.5 \mathrm{wt} \%$ solutions of $\mathrm{CX}-\mathrm{R}$ derivatives, plain PLA and PLA/CX-R nanocomposites in $\mathrm{CH}_{2} \mathrm{Cl}_{2}$ and dried under high vacuum at room temperature. IR spectra were collected at given intervals by adding 16 scans at $4 \mathrm{~cm}^{-1}$ resolution. Isothermal crystallizations were studied for samples melted at $190^{\circ} \mathrm{C}$ for complete clearing of crystals. The samples were then cooled down and kept at the desired temperature for 1 hour (procedure I). Alternatively, the melted samples were cooled down to $100^{\circ} \mathrm{C}$ and crystallized isothermally as described above. The temperature was then increased $\left(10^{\circ} \mathrm{C} \cdot \mathrm{min}^{-1}\right)$ to 110 and then to $120^{\circ} \mathrm{C}$, and samples were crystallized at both respective temperatures for $1 \mathrm{~h}$ (procedure II). Comparative analysis was carried out for spectra recorded in transmission mode as well as for their second derivatives.

Nanomechanical properties on the surface and at the cross-section of the compression molded thin $(0.5 \mathrm{~mm})$ films of PLA and PLA/CX-R were determined with a G-200 Nano Indenter (MTS Nano Instruments/KLA-Tencor Corporation; Milpitas, California, United States) equipped with TestWorksPro 4 software. The data analysis with the Analyst program was based on Oliver and Pharr's approach [35]. The impressions were made with a Berkovich type indenter with a half angle equal to $65.3^{\circ}$ and a radius of roundness $<20 \mathrm{~nm}$. The studies were carried out using two methods: CSM (Continuous Stiffness Measurement) and BASIC [36]. The CSM method is based on continuous measurement of the stiffness $(S)$ during the material penetration to estimate hardness $(H)$ and modulus of elasticity $(E)$ of the material as a function of penetration depth $(h)$. The test was used to measure the mechanical properties of the specimens from the front with 9 prints per sample (penetration depth $1500 \mathrm{~nm}$ ). BASIC method was used to map the mechanical properties from the front at the maximum load point. Maps of $E$ and $H$ were obtained with 100 indents in a $10 \times 10$ matrix with a step of $20 \mu \mathrm{m}$.

\section{Results and discussion \\ 3.1. Synthesis of $C X-R$ and preparation of PLA/CX-R blends}

Thiol compounds with heterorganic groups being either donors or acceptors of hydrogen bonds $(\mathrm{COOH}$, $\mathrm{COOMe}, \mathrm{OH}$ ), were grafted onto 1,3,5,7-tetravinyl1,3,5,7-tetramethyl-cyclotetrasiloxane through thiolene addition (Figure 2). All the obtained products were purified by column chromatography and characterized using NMR spectroscopies (Table 1). All $\mathrm{CX}-\mathrm{R}$ were very viscous liquids that solidified but did not crystallize on cooling.

Cyclotetrasiloxanes with two different substituents at silicon atoms are typically mixtures of four 
Table 1. Reaction yields and spectroscopic data for CX-R.

\begin{tabular}{|c|c|c|c|c|}
\hline \multirow{2}{*}{ CX-R } & \multirow{2}{*}{$\begin{array}{c}\mathbf{Y} \\
{[\%]}\end{array}$} & \multicolumn{3}{|c|}{$\begin{array}{c}\delta \\
{[p p m]:}\end{array}$} \\
\hline & & ${ }^{1} \mathrm{H}$ NMR & ${ }^{13} \mathrm{C}$ NMR & ${ }^{29} \mathrm{Si}$ NMR \\
\hline $\mathrm{CX}-\mathrm{COOH}$ & 32 & $\begin{array}{l}0.07-0.14\left(\mathrm{~s},-\mathrm{Si}-\underline{\mathrm{CH}_{3}}\right) \\
0.84-0.9\left(\mathrm{~m},-\mathrm{Si}-\mathrm{CH}_{2}-\mathrm{CH}_{2}-\mathrm{S}-\right) \\
2.6-2.67\left(\mathrm{~m},-\mathrm{Si}-\mathrm{CH}_{2}-\mathrm{CH}_{2}-\mathrm{S}-\right) \\
3.2-3.25\left(\mathrm{~m},-\mathrm{S}-\mathrm{CH}_{2}-\mathrm{COOH}\right)\end{array}$ & $\begin{array}{l}0.6\left(-\mathrm{Si}-\boldsymbol{C} \mathrm{H}_{3}\right) \\
17.08\left(-\mathrm{Si}-\underline{\boldsymbol{C}} \mathrm{H}_{2}-\mathrm{CH}_{2}-\mathrm{S}-\right) ; \\
27.07\left(-\mathrm{S}-\underline{\boldsymbol{C}} \mathrm{H}_{2}-\mathrm{COOH}\right) \\
33.5\left(-\mathrm{Si}-\mathrm{CH}_{2}-\underline{\boldsymbol{C}} \mathrm{H}_{2}-\mathrm{S}-\right) ; \\
176.4(-\underline{\boldsymbol{C}}-\mathbf{O O H})\end{array}$ & $-21.45\left(-\mathrm{CH}_{2} \mathrm{SiO}_{3 / 2}\right)$ \\
\hline $\mathrm{CX}-\mathrm{COOMe}$ & 62 & $\begin{array}{l}0.08-0.18\left(\mathrm{~s}, \underline{\mathrm{CH}_{3}}-\mathrm{Si}-\right) \\
0.88-0.92\left(\mathrm{~m},-\mathrm{Si}-\underline{\mathrm{CH}_{2}}-\mathrm{CH}_{2}-\right) ; \\
2.67-2.70\left(\mathrm{~m},-\mathrm{CH}_{2}-\underline{\mathrm{CH}} \mathrm{H}_{2}-\mathrm{S}-\right) ; \\
3.17-3.24\left(\mathrm{~m},-\mathrm{S}-\underline{\mathrm{CH}} \underline{2}_{2}-\mathrm{C}(\mathrm{O}) \mathrm{O}-\right) ; \\
3.61(\mathrm{~s},-\mathrm{O}-\underline{\mathrm{CH}} \underline{3})\end{array}$ & $\begin{array}{l}-1.33\left(\underline{\boldsymbol{C}} \mathrm{H}_{3}-\mathrm{Si}-\right) ; \\
17.05\left(-\mathrm{Si}-\underline{\boldsymbol{C}} \mathrm{H}_{2}-\mathrm{CH}_{2-}\right) ; \\
26.7\left(-\mathrm{S}-\underline{\boldsymbol{C}} \mathrm{H}_{2}-\mathrm{C}(\mathrm{O}) \mathrm{O}-\right) ; \\
32.4\left(-\mathrm{CH}_{2}-\underline{\boldsymbol{C}} \mathrm{H}_{2}-\mathrm{S}-\right) ; \\
51.3\left(-\mathrm{O}-\underline{\boldsymbol{C}} \mathrm{H}_{3}\right) \\
170.3(\underline{\boldsymbol{C}}(\mathrm{O}) \mathrm{O})\end{array}$ & $-21.49,-23,66\left(-\mathrm{CH}_{2} \mathrm{SiO}_{3 / 2}\right)$ \\
\hline $\mathrm{CX}-\mathrm{OH}$ & 39 & $\begin{array}{l}0.07-0.10\left(\mathrm{~s},-\mathrm{Si}-\mathrm{CH}_{3}\right) \\
0.82-0.87\left(\mathrm{~m},-\mathrm{Si}-\mathrm{CH}_{2}-\mathrm{CH}_{2}-\right) ; \\
2.52-2.58\left(\mathrm{~m}, \mathrm{Si}-\mathrm{CH}_{2}-\underline{C H}_{2}-\mathrm{S}-\underline{\mathrm{CH}_{2}}-\right) ; \\
3.56-3.57\left(\mathrm{~m},-\mathrm{S}-\mathrm{CH}_{2}-\underline{\mathrm{CH}}_{2}-\mathrm{OH}\right) ; \\
4.22\left(\mathrm{~s},-\mathrm{CH}_{2}-\underline{\mathrm{OH}}\right)\end{array}$ & $\begin{array}{l}-0.97\left(\underline{\boldsymbol{C}} \mathrm{H}_{3}-\mathrm{Si}-\right) \\
17.9\left(-\mathrm{Si}-\underline{\boldsymbol{C}} \mathrm{H}_{2}-\mathrm{CH}_{2}-\right) ; \\
26.2\left(-\mathrm{S}-\underline{\boldsymbol{C}} \mathrm{H}_{2}-\mathrm{CH}_{2}-\mathrm{OH}\right) ; \\
34.2\left(-\mathrm{CH}_{2}-\underline{\boldsymbol{C}} \mathrm{H}_{2}-\mathrm{S}-\right) ; \\
61.4\left(-\mathrm{S}-\mathrm{CH}_{2}-\underline{\boldsymbol{C}} \mathrm{H}_{2}-\mathrm{OH}\right)\end{array}$ & $-21.48\left(-\mathrm{CH}_{2} \mathrm{SiO}_{3 / 2}\right)$ \\
\hline $\mathrm{CX}-(\mathrm{OH})_{2}$ & 48 & $\begin{array}{l}0.12-0.16\left(\mathrm{~s},-\mathrm{Si}-\mathrm{CH}_{3}\right) \\
0.90-0.91\left(\mathrm{~m},-\mathrm{Si}-\underline{\mathrm{CH}_{2}}-\right) ; \\
2.53-2.76\left(\mathrm{~m},-\underline{\mathrm{CH}_{2}-\mathrm{S}}-\underline{\mathrm{CH}_{2}}-\right) ; \\
3.71-3.72\left(\mathrm{~m},-\mathrm{CH}_{2}-\underline{\mathrm{CH}}(\mathrm{OH})-\mathrm{CH}_{2}-\right) \\
3.5-3.6\left(\mathrm{~m},-\mathrm{CH}(\mathrm{OH})-\mathrm{CH}_{2}-\mathrm{OH}\right)\end{array}$ & $\begin{array}{l}-1.6\left(-\mathrm{Si}-\underline{\boldsymbol{C}} \mathrm{H}_{3}\right) ; \\
17.58\left(-\mathrm{Si}-\underline{\boldsymbol{C}} \mathrm{H}_{2}-\mathrm{CH}_{2}-\mathrm{S}-\right) ; \\
26.7\left(-\mathrm{S}-\underline{\boldsymbol{C}} \mathrm{H}_{2}-\mathrm{CH}(\mathrm{OH})-\right) ; \\
34.8\left(-\mathrm{Si}-\mathrm{CH}_{2}-\underline{\boldsymbol{C}} \mathrm{H}_{2}-\mathrm{S}-\right) ; \\
64.7\left(-\underline{\boldsymbol{C}} \mathrm{H}_{2}-\mathrm{OH}\right) ; \\
71.4\left(-{ }^{-} \mathrm{CH}_{2}-\underline{\boldsymbol{C}} \mathrm{H}(\mathrm{OH})-\mathrm{CH}_{2}-\right)\end{array}$ & $-21.24\left(-\mathrm{CH}_{2} \mathrm{SiO}_{3 / 2}\right)$ \\
\hline
\end{tabular}

$Y$ - reaction yield after the column chromatography purification

stereoisomers: all-cis, cis-cis-trans, cis-trans-cis, and all-trans [37] of different molar abundance. Yet, owing to the substantial flexibility of siloxane bonds and alkyl chains, this feature is not important for interactions of PLA with CX-R. In the single case of

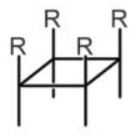

all-cis

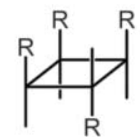

cis-cis-trans

${ }^{1} \mathrm{H}$ NMR

$$
-\mathrm{S}-\mathrm{CH}_{2}
$$

1,3,5,7-tetra[2-(carboxymethylthio)ethyl]-1,3, 5,7tetramethyl-cyclotetrasiloxane $(\mathrm{CX}-\mathrm{COOH})$, we were able to obtain a fraction (consisting of $91.6 \%$ of the total $31.4 \%$ yield of CX-COOH after the column separation) enriched in the isomer cis-cis-trans.

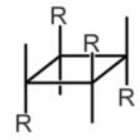

all-trans

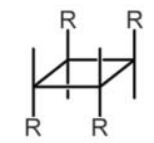

cis-trans-cis

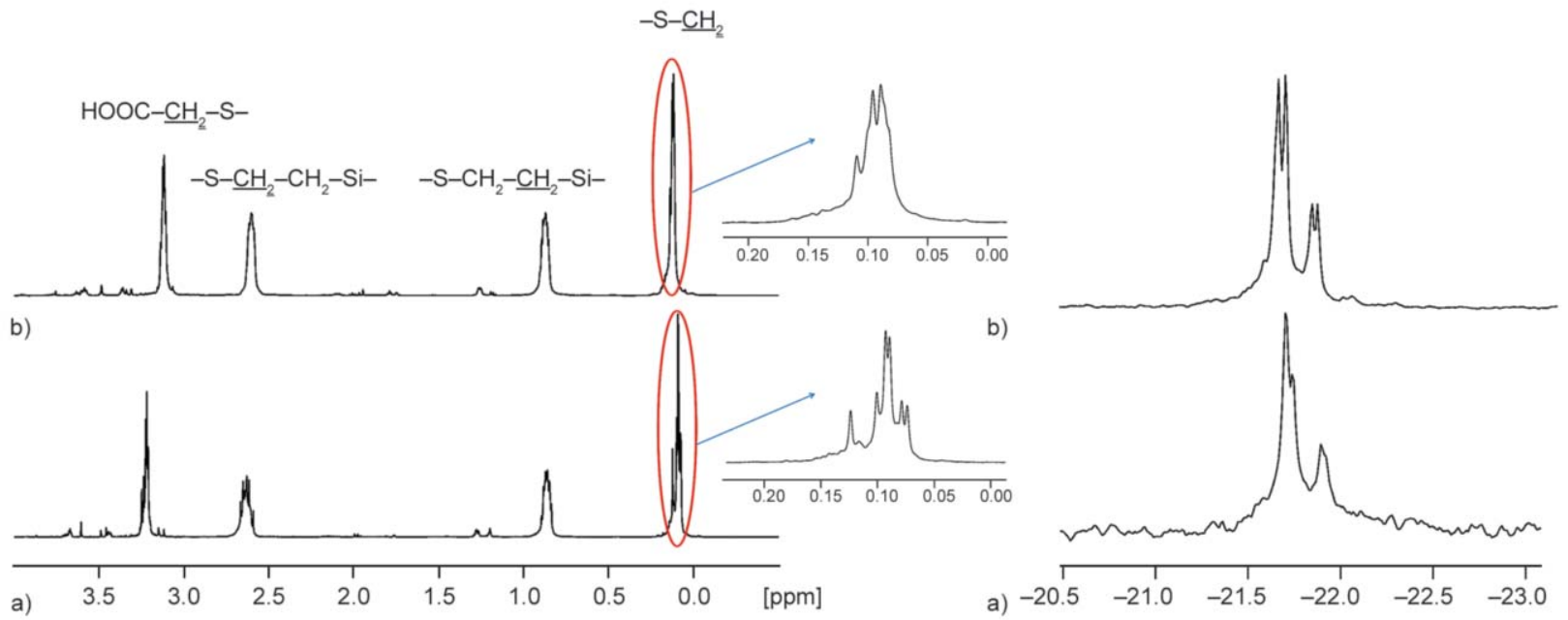

Figure 3. ${ }^{1} \mathrm{H}$ and ${ }^{29} \mathrm{Si}$ NMR spectra of fractionated $\mathrm{CX}-\mathrm{COOH}$ : a) fraction enriched in isomer cis-cis-trans; b) mixture of isomers. 
The assignment was based on the number of resonance lines in ${ }^{1} \mathrm{H}$ and ${ }^{29} \mathrm{Si}$ NMR spectra (Figure 3) and the data published for analogous systems [37-41]. Mixtures of PLA and CX-R were prepared by solution blending. Solutions of PLA became cloudy on addition of $\mathrm{CX}-\mathrm{COOH}, \mathrm{CX}-\mathrm{OH}$ and $\mathrm{CX}-(\mathrm{OH})_{2}$ but not in the presence of CX-COOMe or CX-Vi. Smallscale tests showed that the turbidity was not induced by pure solvents (THF or $\mathrm{MeOH}$ ) at amounts equal to those added with $\mathrm{CX}-\mathrm{R}$. Vacuum dried specimens of PLA/CX-R were hot pressed into $0.5 \mathrm{~mm}$ thick samples and most of them were fairly clear. Distribution of CX-R was examined using energy dispersive $\mathrm{X}$-ray analysis combined with scanning electron microscopy. SEM-EDS mapping of silicon atoms (Figure 4) showed that samples prepared with $\mathrm{CX}-\mathrm{COOH}$ contain domains enriched with organosilicon compounds that become more defined on the increase of the amount of $\mathrm{CX}-\mathrm{COOH}$. This feature may be explained by interactions of side donor/acceptor carboxyl groups of $\mathrm{CX}-\mathrm{COOH}$ with both PLA chains and other molecules of $\mathrm{CX}-\mathrm{COOH}$. The dimeric structures are more stable than hydrogen bonds with carbonyl groups of PLA chains. CX-Vi, $\mathrm{CX}-\mathrm{COOMe}$ and $\mathrm{CX}-\mathrm{OH}$ were well dispersed in the polymer matrix. Distribution of $\mathrm{CX}-(\mathrm{OH})_{2}$ having two hydroxyl moieties at each side group in a 'bidentate' arrangement was quite good. Yet, small domains with slightly higher concentration of this additive can be found in the studied area. The effect may be associated with micro-precipitation of PLA macromolecules hydrogen bonded with $\mathrm{CX}-(\mathrm{OH})_{2}$ (addition of $\mathrm{MeOH}$ in the same proportion to PLA and $\mathrm{CH}_{2} \mathrm{Cl}_{2}$ did not cause a visible precipitation of the polymer).

Direct light transmittance through PLA/CX-R was characterized quantitatively in the range of 200 $1000 \mathrm{~nm}$. It depends on the type of functional group $\mathrm{R}$ and the concentration of the additive (Figure 5). Transparency of plastic sheets is defined as capability to transmit light within $540-560 \mathrm{~nm}$ [42]. Samples of PLA admixed with CX-COOMe at $\leq 5 \mathrm{wt} \%$ were thus as transparent as the native PLA. It was also found that PLA/CX-COOMe absorb light at $\lambda=$ $250-340 \mathrm{~nm}$. The region is close to the most energetic band of natural UV light (UV-B, 280-315 nm), that is responsible for photochemical degradation of materials. Combination of clarity and absorption of specific wavelength of light are valuable features, e.g. in packing materials. The filter effect can be ascribed to the presence of carbonyl groups (neat $\mathrm{CX}-\mathrm{COOMe}$ and $\mathrm{CX}-\mathrm{COOH}$ absorb light at $250-340 \mathrm{~nm}$ ). $\mathrm{CX}-\mathrm{COOH}$ inclusions in PLA, evidenced with SEMEDS, caused a decrease of light transmission over the studied region of the spectrum. Interestingly, the sample containing $10 \mathrm{wt} \%$ of $\mathrm{CX}-\mathrm{COOH}$ appear to be more transparent to light of $\lambda>500 \mathrm{~nm}$ than the one admixed with $5 \mathrm{wt} \%$ of the cyclosiloxane. The observed effect can be explained by an increased phase separation of regions enriched with $\mathrm{CX}-\mathrm{COOH}$. Clarity of PLA/CX-Vi (2 wt\%) and PLA/CX-OH $(1 \mathrm{wt} \%)$ is close to that of PLA. Larger amounts of $\mathrm{CX}-\mathrm{OH}(2-4 \mathrm{wt} \%)$ made PLA slightly less transparent over the studied wavelength range. $\mathrm{CX}-(\mathrm{OH})_{2}$ caused a substantial decrease of light transmittance through PLA matrix. At $4 \mathrm{wt} \%$ it made the polymer opaque over the entire UV/Vis range.

\subsection{Broadband dielectric relaxation}

Modification of PLA with $\mathrm{CX}-\mathrm{OH}$ and $\mathrm{CX}-\mathrm{COOH}$ additives is clearly reflected in the frequency-temperature plots of the imaginary component of complex permittivity (Figure 6), where the characteristic relaxation processes are indicated with arrows. A strong $\alpha$-relaxation associated with the glass transition is the most prominent feature of the dielectric spectra, with almost identical shape in plain PLA and PLA/CX-R mixtures. Another relaxation ( $\beta$-process), related to local motion in the polymer matrix, also appears in all the samples. It is hardly visible at this scale and temperature, but it undergoes noticeable modifications depending on the $\mathrm{CX}-\mathrm{R}$ additive. Modifications of the dielectric response are also visible at high temperatures $\left(>100^{\circ} \mathrm{C}\right)$. They become larger with growing concentration of the CX-R additive, which is why relatively large concentrations were chosen for display in Figure $6(4 \mathrm{wt} \% \mathrm{CX}-\mathrm{OH}$ and $5 \mathrm{wt} \%$ $\mathrm{CX}-\mathrm{COOH})$. A distinct case is PLA admixed with a large amount of $\mathrm{CX}-\mathrm{COOH}$ ( 5 and $10 \mathrm{wt} \%$ ), where an additional $\gamma$-relaxation appears at low temperatures (Figure 6c). The $\varepsilon^{\prime \prime}(f)$ plots at a few selected temperatures are shown in Figure 7 for better visualization of the observed relaxation processes. The standard Havriliak-Negami formula with conductivity term (Equation (1)) [43] was fitted to the experimental data to support more quantitative analysis:

$$
\varepsilon^{*}(\omega)-\varepsilon_{\infty}=-i \frac{\sigma_{0}}{\varepsilon_{0} \omega^{\mathrm{s}}}+\sum_{\mathrm{k}} \frac{\Delta \varepsilon_{\mathrm{k}}}{\left(1+\left(i \omega \tau_{\mathrm{k}}\right)^{\alpha_{\mathrm{k}}}\right)^{\beta_{\mathrm{k}}}}
$$



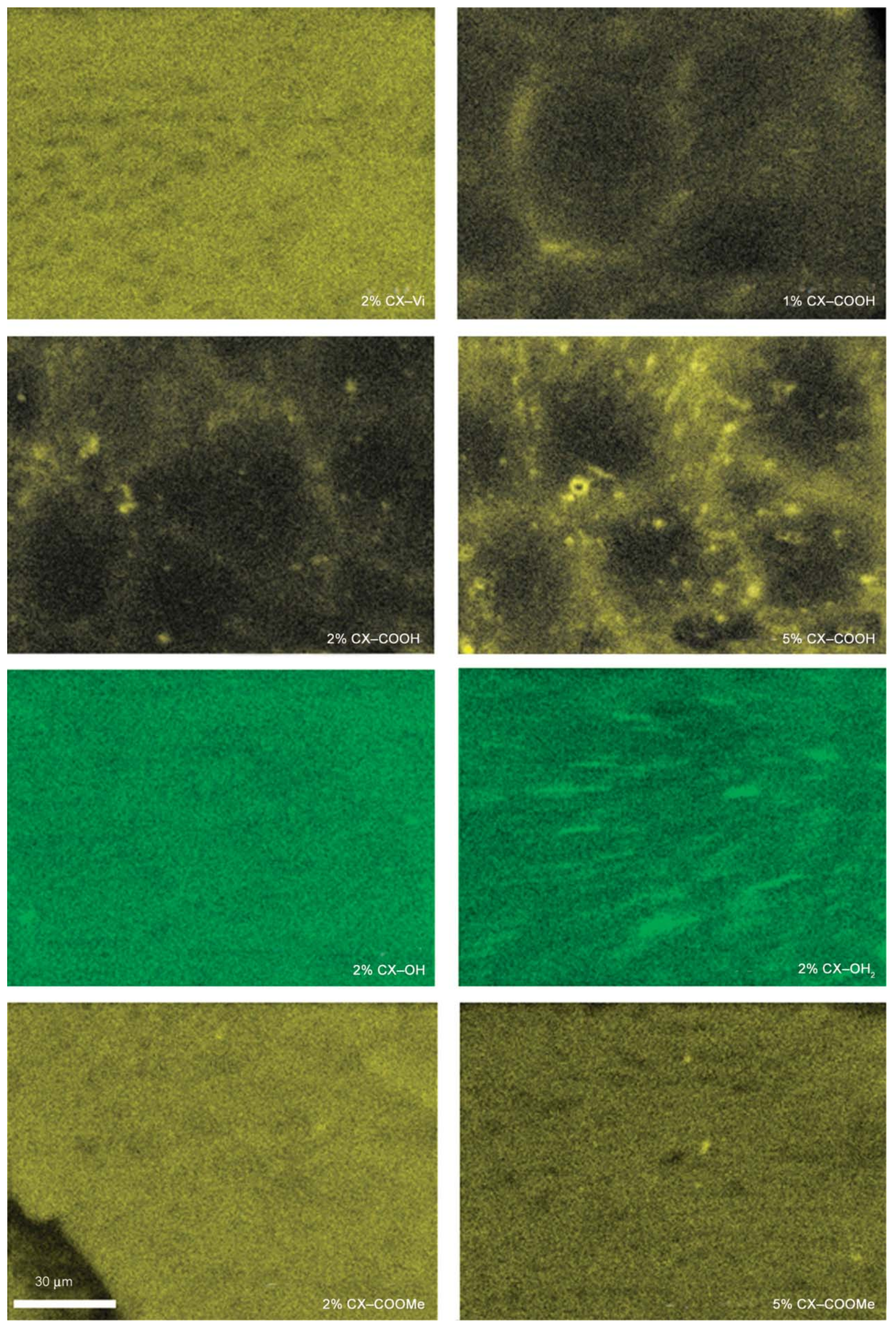

Figure 4. Distribution of Si atoms (bright field) in samples of PLA admixed with CX-R, as indicated by SEM-EDS. 

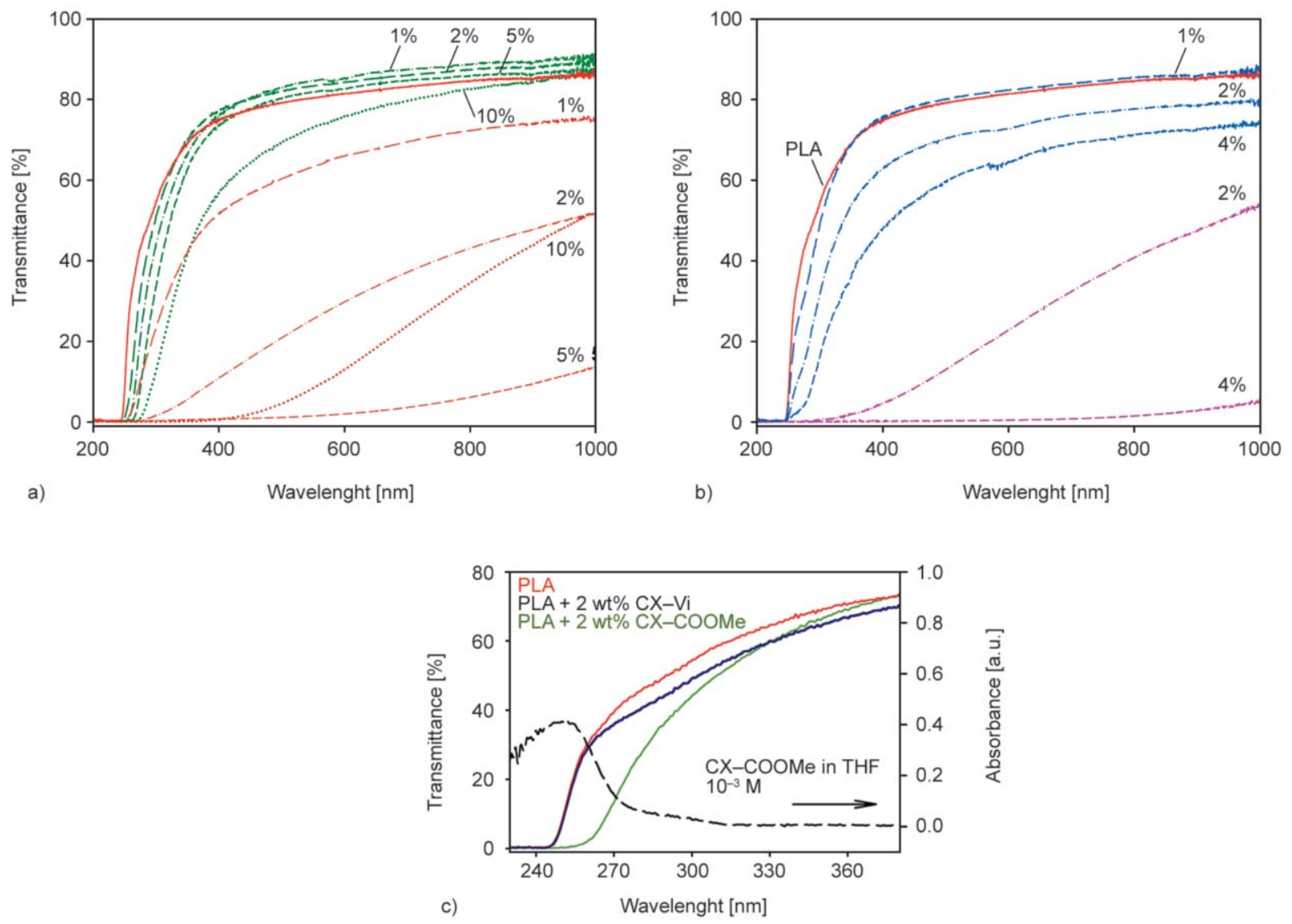

Figure 5. Direct light transmittance measured for the compression molded PLA/CX-R: (a) PLA (-) admixed with $\mathrm{CX}-\mathrm{COOMe}(-)$ and $\mathrm{CX}-\mathrm{COOH}(-)$; (b) PLA (-) admixed with $\mathrm{CX}-\mathrm{OH}(-)$ and $\mathrm{CX}-(\mathrm{OH})_{2}(-)$; (c) comparison of transmittance through selected thin films and absorbance of $10^{-3} \mathrm{M}$ solution of CX-COOMe in THF.

where $\varepsilon_{0}$ - vacuum permittivity, $\omega$ - radial frequency, $\varepsilon_{\infty}=\varepsilon^{\prime}$ at $f \rightarrow \infty, \Delta \varepsilon$ - difference between the highfrequency and low-frequency values of permittivity for a given relaxation, $\tau$ - relaxation time, $\alpha$ and $\beta$ shape parameters, $\sigma_{0}$ - direct-current conductivity, $s$-parameter related to non-ohmic effects.

The $\alpha$-process, which clearly dominates the response at 60,65 and $75^{\circ} \mathrm{C}$, is almost identical in pure and admixed PLA. The rapid shift of that process towards low frequencies at temperatures below $47^{\circ} \mathrm{C}$ is associated with quenching of cooperative motions and with the vitrification process. A similar behaviour was also observed in other studies of PLA [25]. This frequency-shifting of the $\alpha$ process progresses somewhat slower in PLA/CX-R matrices $-c f$. temperatures 47 and $40^{\circ} \mathrm{C}$ in Figures $7 \mathrm{a}$ and $7 \mathrm{~b} / 7 \mathrm{c}$. After vanishing of the dominant $\alpha$-process at low temperatures, the secondary processes appear. The $\beta$-relaxation visible in all the studied matrices is associated with the motions of local polar groups in PLA. Addition of $\mathrm{CX}-\mathrm{OH}$ modifies that process, as seen in Figures $7 \mathrm{a} / 7 \mathrm{~b}$ at 47 and $40^{\circ} \mathrm{C}$. In PLA/CX-COOH, dielectric response at the same temperatures reveals another relaxation ( $\gamma$-process) at lower frequencies, which somewhat hides the $\beta$-process (Figure 7b).

More differences between the dielectric spectra of plain and admixed PLA are visible at high temperatures, where cold crystallization is expected $(T=85$, 95 and $115^{\circ} \mathrm{C}$ ). In plain PLA, cold crystallization is reflected in the modification of the $\alpha$-process: the frequency shift of that process is slower than at lower temperatures; its amplitude decreases as well $\left(T=95^{\circ} \mathrm{C}\right)$. These observations are consistent with other studies, where modification of the $\alpha$-process due to cold crystallization was observed [25]. The effect of the CX-R additives on the $\alpha$-process in PLA matrix is particularly well visible in the permittivity-temperature plot at high frequencies (Figure 8).

The same plot also reveals the influence of concentration of the additive on that relaxation process. For a better insight, dielectric response of PLA admixed with different amounts of the additive is shown at selected low and high temperatures at which the additive has a significant impact on the dielectric response (Figure 9). Figure 9a displays the data for $\mathrm{PLA} / \mathrm{CX}-\mathrm{COOH}$ at four concentration levels $(0,2$, 

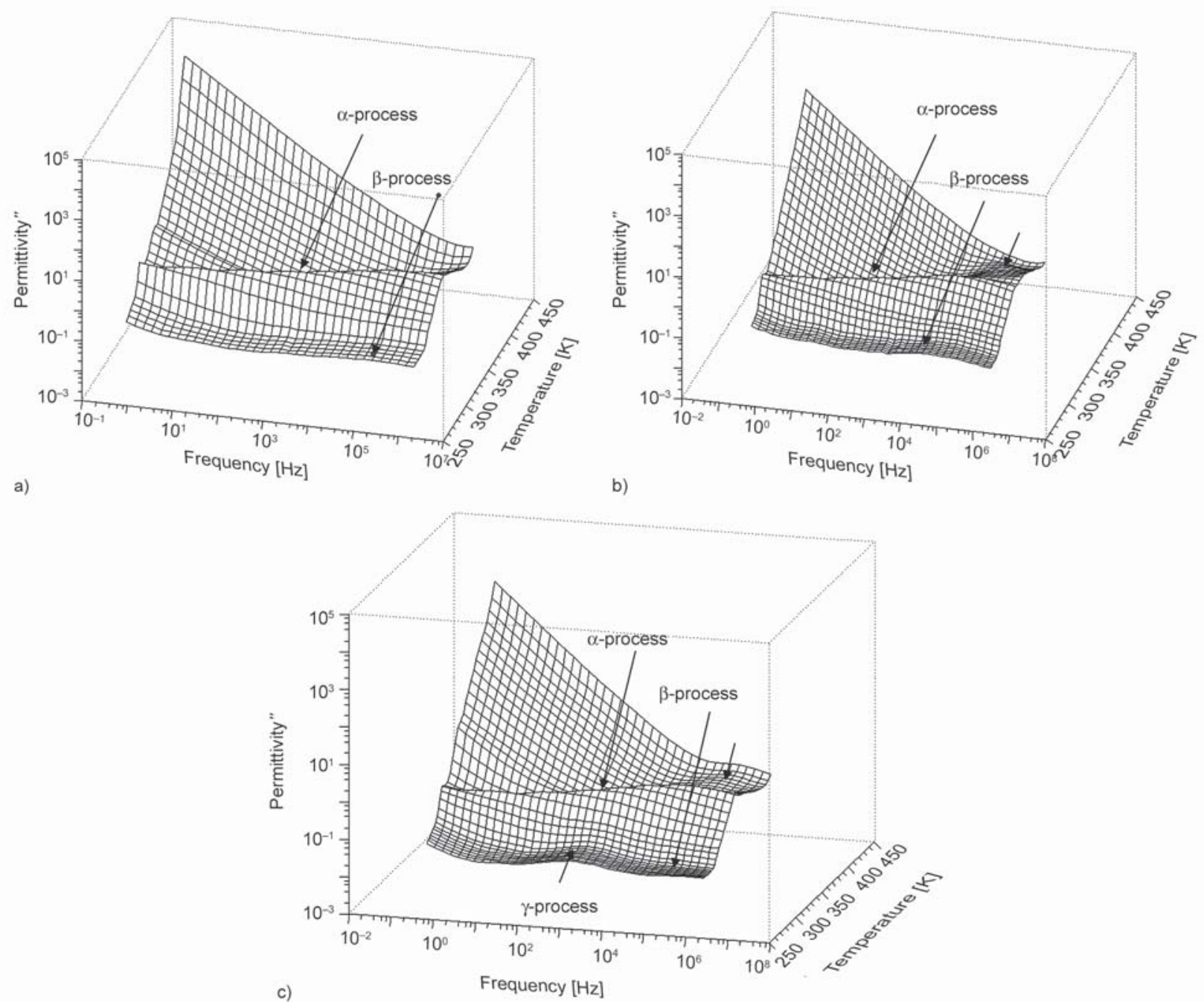

Figure 6. Dielectric response of (a) plain PLA, (b) PLA $+4 \mathrm{wt} \% \mathrm{CX}-\mathrm{OH}$, and (c) PLA $+5 \mathrm{wt} \% \mathrm{CX}-\mathrm{COOH}$ : the imaginary part of complex permittivity $v s$. frequency and temperature. Arrows indicate the characteristic relaxations.

5 and $10 \mathrm{wt} \%$ ) and the temperatures of 30 and $115^{\circ} \mathrm{C}$ (inset). For comparison, data collected at the same temperatures for PLA/CX-OH at concentrations of 0,2 and $4 \mathrm{wt} \%$ is also presented (Figure $9 \mathrm{~b}$ ). Figure 9 a clearly demonstrates the dependence of the strength of the $\gamma$-process on the amount of the additive in PLA/CX-COOH. Interestingly, dielectric response at $2 \%$ concentration, where both the $\gamma$ and $\beta$ processes occur next to each other, is notably different from the response recorded at higher concentrations. In the mixtures with 5 and $10 \mathrm{wt} \%$ of $\mathrm{CX}-\mathrm{COOH}$, the $\gamma$-process occurs at somewhat different frequency and its amplitude substantially grows with increasing concentration of the additive. The observed process is therefore related to coordination of carboxyl groups in the $\mathrm{CX}-\mathrm{COOH}$ additive.

The PLA/CX-OH matrix presents a different behaviour (Figure 9b). A modification of the $\beta$ process is also visible at low temperatures, but it is not accompanied by any additional processes. At the high-temperature region, where the $\alpha$-process undergoes a modification along with increasing concentration of $\mathrm{CX}-\mathrm{OH}$, lessening of the amplitude of the process occurs at somewhat lower temperature $\left(85^{\circ} \mathrm{C}\right)$ than in plain PLA $\left(95^{\circ} \mathrm{C}\right)$. Thus, a small decrease of cold crystallization temperature due to the additive may be postulated.

Summing up, a small addition of $\mathrm{CX}-\mathrm{COOH}$ or $\mathrm{CX}-\mathrm{OH}$ modifies the dielectric response to some extent, both the $\beta$-process at low temperatures and the $\alpha$-process at high temperatures - particularly near $100^{\circ} \mathrm{C}$ where the $\alpha$-relaxation visibly changes with increasing content of $\mathrm{CX}-\mathrm{OH}$ or $\mathrm{CX}-\mathrm{COOH}$. This observation, along with complementary experiments, points towards higher potential for cold crystallization. Larger concentrations of $\mathrm{CX}-\mathrm{COOH}$ additive (above $2 \mathrm{wt} \%$ ) display additional relaxation processes at low and high temperatures, whose amplitudes 

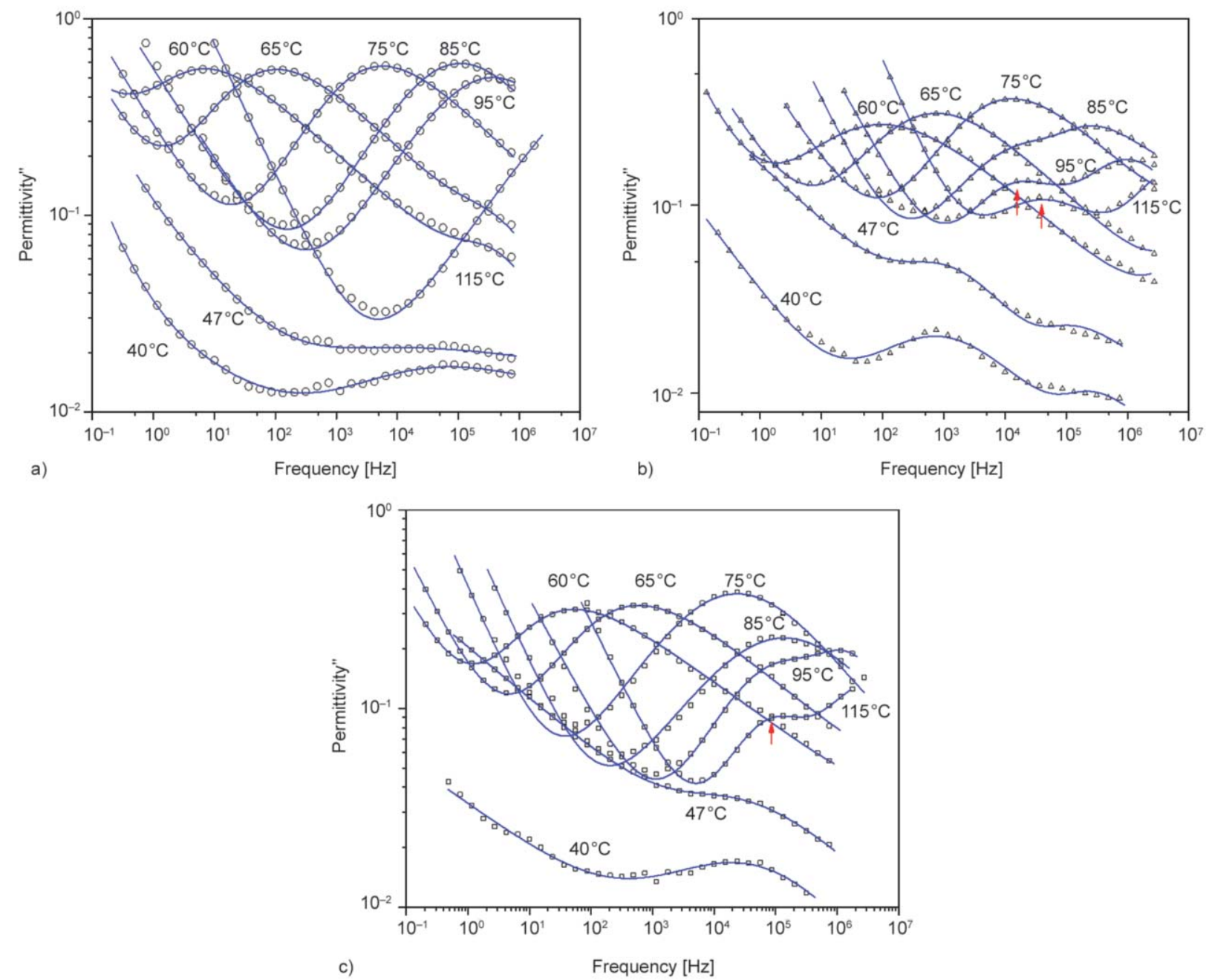

Figure 7. Plots of $\varepsilon^{\prime \prime}(f)$ at a few selected temperatures, visualizing the relaxation processes: (a) plain PLA, (b) PLA + $5 \mathrm{wt} \% \mathrm{CX}-\mathrm{COOH},(\mathrm{c}) \mathrm{PLA}+4 \mathrm{wt} \% \mathrm{CX}-\mathrm{OH}$.

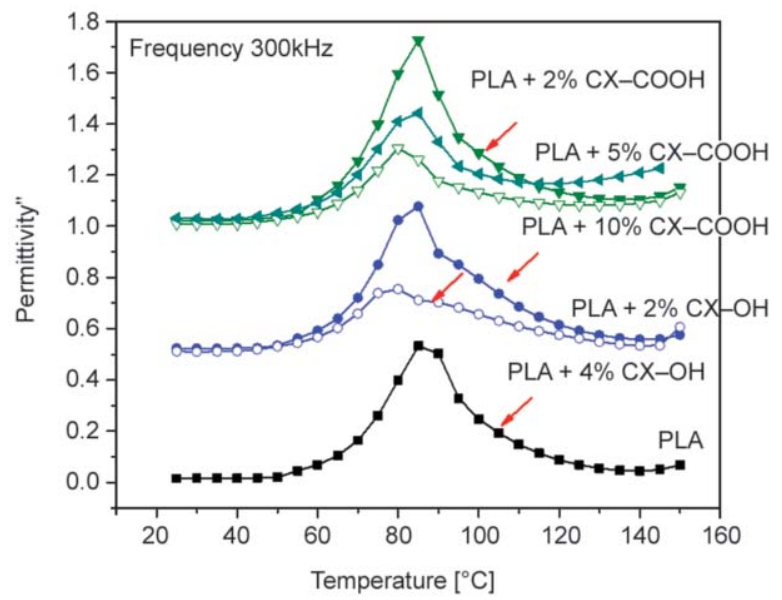

Figure 8. Influence of CX-R additives on the strength of the $\alpha$-relaxation in PLA. Permittivity-temperature plots at $f=300 \mathrm{kHz}$ for a few concentration levels of the additives. Plots for admixed PLA are shifted by the values of 0.5 (PLA/CX-OH) and 1.0 (PLA/ $\mathrm{CX}-\mathrm{COOH}$ ). grow significantly with increasing concentration of $\mathrm{CX}-\mathrm{COOH}$. Correlation of this behaviour with the complementary studies ( $c f$. Figures 4 and 10) supports interpreting it as a reflection of phase separation and vanishing of cold crystallization.

\subsection{Thermal properties of PLA/CX-R blends}

The presence of $\mathrm{CX}-\mathrm{R}$ in PLA matrix led to a range of complex phenomena related to differences in chain dynamics but they did not influence the thermal stability of PLA. Thermogravimetric analysis (not shown) of neat PLA and its mixtures with CX-R indicated that thermal stability of PLA and the composites is the same $\left[T_{\mathrm{d} 5}=330^{\circ} \mathrm{C}, T_{\max }=360^{\circ} \mathrm{C}\right.$ (decomposition rate $10 \% \cdot \mathrm{min}^{-1}$ )] under $\mathrm{N}_{2}$ at heating rate of $10^{\circ} \mathrm{C} \cdot \mathrm{min}^{-1}$. Interesting results were obtained for the behaviour of PLA/CX-R during DSC runs carried out with a temperature ramp. DSC analysis indicated that the native PLA containing $\sim 3 \%$ molar 

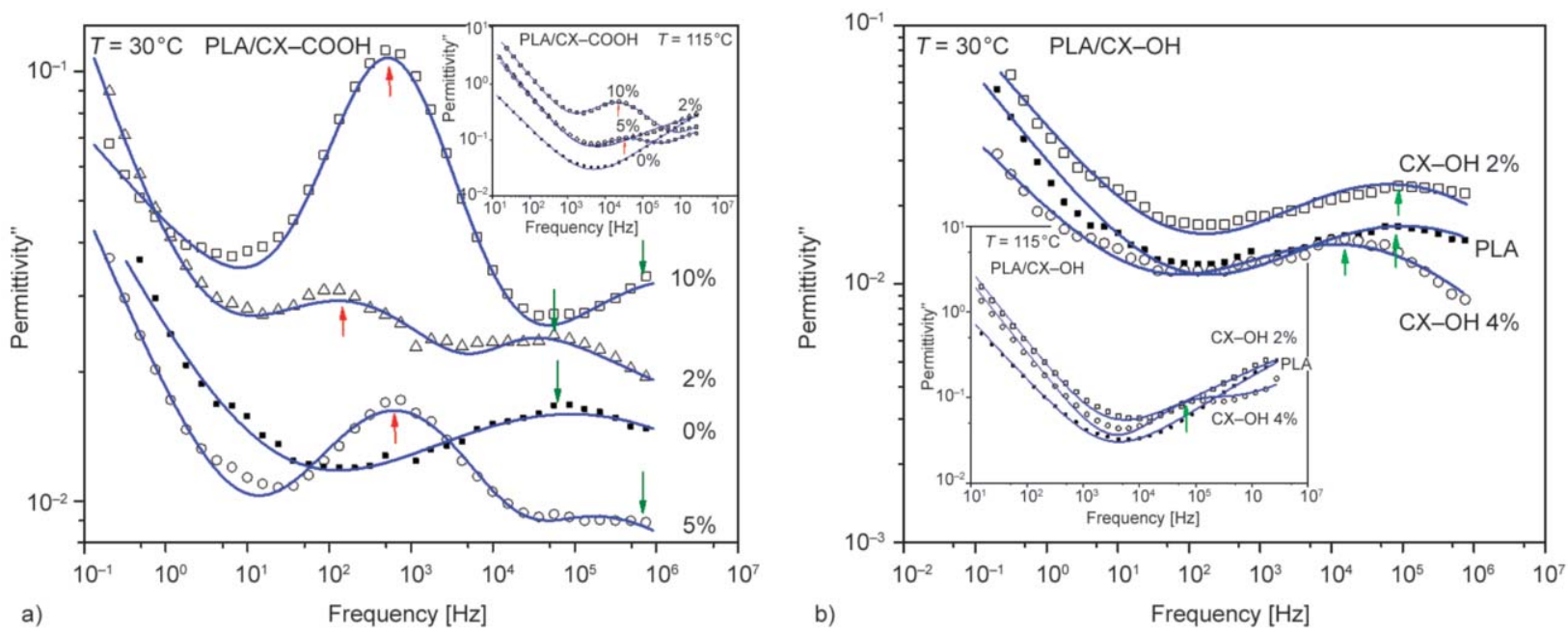

Figure 9. Dielectric response of PLA/CX-R at different concentration levels: (a) PLA/CX-COOH at $T=30^{\circ} \mathrm{C}$ (inset: $T=$ $115^{\circ} \mathrm{C}$ ); (b) PLA/CX-OH at $T=30^{\circ} \mathrm{C}$ (inset: $T=115^{\circ} \mathrm{C}$ ).

amount of D-lactide units did not crystallize on cooling from melt at $10^{\circ} \mathrm{C} \cdot \mathrm{min}^{-1}$ nor $2^{\circ} \mathrm{C} \cdot \mathrm{min}^{-1}$. Due to the same reason, enthalpy of cold crystallization $\left(\Delta H_{\mathrm{cc}}\right)$ of samples cooled down from melt at $10^{\circ} \mathrm{C} \cdot \mathrm{min}^{-1}$ and heated again at $10^{\circ} \mathrm{C} \cdot \mathrm{min}^{-1}$ is very small. The degree of crystallinity $(X)$ achieved under the applied conditions is close to $5 \%$ (with respect to the enthalpy of melting of a completely crystallized PLLA; 93.1 J/g [44]).

Addition of CX-R did not improve PLA crystallization from melt, yet their presence clearly influenced the process of cold crystallization. It is known, that nucleation of PLA and the rate of crystal growth are determined, especially at the early stages of the process, by the molecular conformation and chain ordering. Initially formed edge-on lamellar crystals develop straightforward growing both parallel and perpendicular to the film surface evolving finally into flat-on hexagonal crystals and spherulites [45]. Localized binding of 2-4 polymer chains by hydrogen bonding with $\mathrm{CX}-\mathrm{R}$ can help to the formation of edge-on crystals. Hydrogen bonds are labile at high temperatures and therefore the observed poor nucleating effectiveness of $\mathrm{CX}-\mathrm{R}$ on cooling since, contrary to the hydrazide or amide nucleators mentioned above, they do not form crystals in the PLA melt. Yet, polymer chains in amorphous samples of PLA/CX-R can gradually gain mobility on heating from $T<T_{\mathrm{g}}$, and the lactide segments bound by supramolecular interactions with CX-R become nuclei of PLA crystals. The combined increase of crystal fraction and lack of a deteriorating effect of CX-R on the thermal resistance and transparency of PLA should be thus stressed. A decrease of thermal stability and poor light transmittance was reported for PLA containing an otherwise effective dihydrazide nucleating agent [46].

Differences in DSC thermograms recorded for samples of PLA/CX-R cooled down at $10^{\circ} \mathrm{C} \cdot \mathrm{min}^{-1}$ from melt to room temperature and heated at $10^{\circ} \mathrm{C} \cdot \mathrm{min}^{-1}$ (Figure 10) can be related to the type of CX-R. The test carried out with CX-Vi of no affinity to PLA did not show any strong effects. However, in the presence
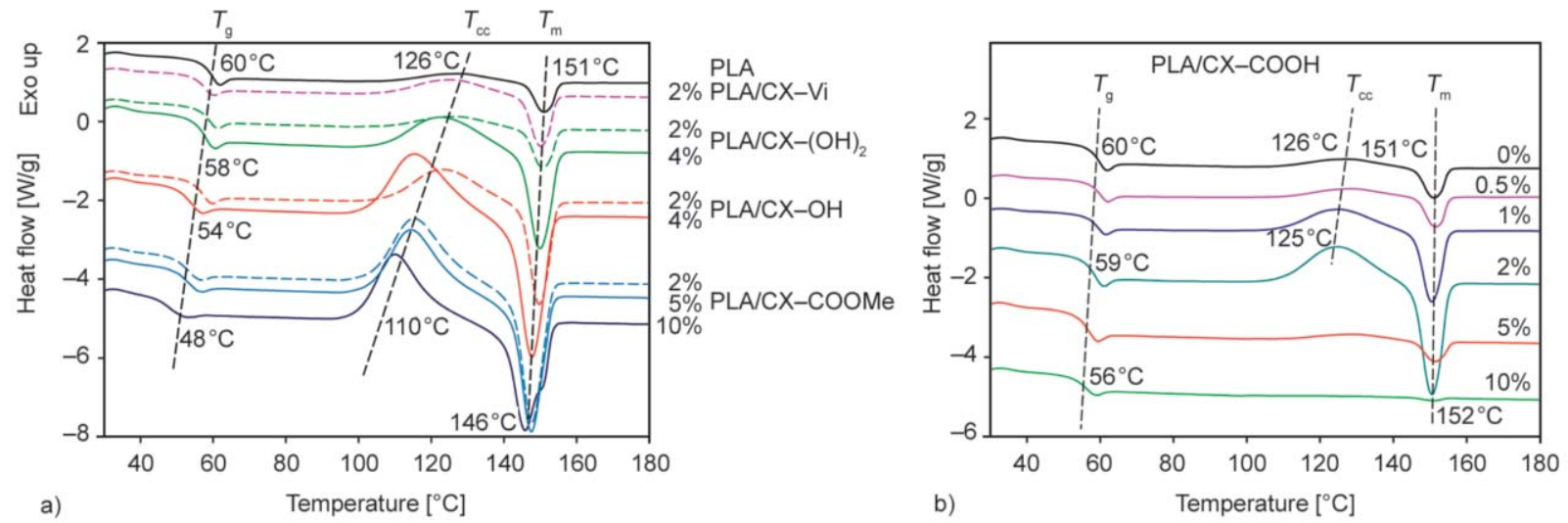

Figure 10. Influence of the type of CX-R for the process of cold crystallization of PLA (DSC, $2^{\text {nd }}$ heating at $\left.10^{\circ} \mathrm{C} \cdot \mathrm{min}^{-1}\right)$. 
of $\mathrm{CX}-\mathrm{OH}, \mathrm{CX}-(\mathrm{OH})_{2}$ and $\mathrm{CX}-\mathrm{COOMe}$ an exothermic peak related to the process of cold crystallization was recorded at $110-140^{\circ} \mathrm{C}$ with a maximum shifted to lower temperatures than that characteristic to PLA. The $\Delta H_{\mathrm{cc}}$ and $\Delta H_{\mathrm{m}}$ of the subsequent melting $\left(T_{\mathrm{m}} \sim\right.$ $150^{\circ} \mathrm{C}$ ) were the same (within the measurement accuracy), which typically indicates that the crystals were formed exclusively during the heating run.

A shift of the glass transition temperature was observed in the presence of CX-R. The effect points to a slight increase of the segmental movement of PLA chains and depends on the type of functional group and the amount of CX-R. Devitrification takes place at lower temperatures for composites containing larger amounts of the additives. The drop of $T_{\mathrm{g}}\left(\Delta T_{\mathrm{g}}\right)$ in the presence of $4 \mathrm{wt} \% \mathrm{CX}-(\mathrm{OH})_{2}$ is smaller $\left(2^{\circ} \mathrm{C}\right)$ than that noted for $4 \mathrm{wt} \% \mathrm{CX}-\mathrm{OH}\left(6^{\circ} \mathrm{C}\right)$ and for $5 \mathrm{wt} \% \mathrm{CX}-\mathrm{COOMe}\left(6^{\circ} \mathrm{C}\right)$. Yet, crystallinity of PLA admixed with $4 \mathrm{wt} \%$ of the hydrogen bond donating $\mathrm{CX}-\mathrm{OH}$ and $\mathrm{CX}-(\mathrm{OH})_{2}$ was, respectively, 25 and $14 \%$. The poorer nucleation despite multiple hydrogen bonding capability of thioglycerol moieties, suggests that too large amount of hydroxyl groups makes more difficult the proper chain alignment. A more substantial decrease of $T_{\mathrm{g}}$, proportional to the concentration of the additive, was recorded for PLA compositions with $\mathrm{CX}-\mathrm{COOMe}$. Yet the thermally induced crystallinity of samples containing CX-COOMe is almost independent (25-29\%) on the amount of the additive ( 2 to $10 \mathrm{wt} \%$ ). The phenomenon may be tentatively linked to the ability of -COOMe groups to act as acceptors/donors of weak hydrogen bonds to the carbonyl oxygens of ester groups $(\mathrm{CH} \cdots \mathrm{O}=\mathrm{C})$. Such interactions play a very important role in stereocomplexes of PLLA and PDLA [47]. Therefore, the total effect of CX-COOMe on PLA would be a resultant of the matrix plastification and supramolecular interactions. The phenomenon will be the subject of extended studies.

An unusual, non-linear effect was noted for mixtures of PLA and $\mathrm{CX}-\mathrm{COOH}$. Analogously to the other $\mathrm{CX}-\mathrm{R}$, a small amount $(0.5-2 \mathrm{wt} \%)$ of $\mathrm{CX}-\mathrm{COOH}$ strongly promoted cold crystallization of the matrix. However, if the concentration of $\mathrm{CX}-\mathrm{COOH}$ was $\geq 5 \mathrm{wt} \%$, then crystallization of PLA was hampered. The effect can be related to strong interactions between the $-\mathrm{COOH}$ groups and polyester backbone as well as to the phase separation and formation of a hydrogen bonded dual network (shown on SEM-EDS micrographs - Figure 4, and confirmed by the results obtained with BDS).

\subsection{Isothermal crystallization of PLA/CX-R - DSC and FTIR studies}

Isothermal crystallization from melt carried out at selected temperatures for PLA admixed with $\mathrm{CX}-\mathrm{R}$ at $2 \mathrm{wt} \%$ suggest that hydrogen bonding from $\mathrm{CX}-\mathrm{OH}$ and $\mathrm{CX}-(\mathrm{OH})_{2}$ affects the mobility of PLA chains and results in faster crystallization of the polyester matrix within the temperature range $90-120^{\circ} \mathrm{C}$. The estimated crystallization half-times (Figure 11a) show clearly the effect of the cyclosiloxane additives. $\mathrm{CX}-\mathrm{COOH}$ and $\mathrm{CX}-\mathrm{COOMe}$ increased the crystallization rate only at high temperatures $\left(120^{\circ} \mathrm{C}\right)$. The isothermal annealing from melt leads to the formation of a thermodynamically preferred polymorph [48-50]. Consequently, a single endothermic peak representing melting of PLA crystals was found for DSC diagrams of samples of PLA and PLA/CX-R crystallized at 110 and $120^{\circ} \mathrm{C}$ (Figure 11b). Structures formed at $110^{\circ} \mathrm{C}$ melt at slightly lower temperatures $\left(T_{\mathrm{m}}=149^{\circ} \mathrm{C}\right)$ than those annealed at $120^{\circ} \mathrm{C}$ $\left(T_{\mathrm{m}}=152^{\circ} \mathrm{C}\right)$. Two endothermic peaks that were observed for all samples (PLA and PLA/CX-R) annealed at 90 and $100^{\circ} \mathrm{C}$, reflect the characteristic melt-recrystallization behaviour leading to the perfection of PLA crystals [48, 51]. The undeveloped crystals formed at $90^{\circ} \mathrm{C}$ tend to melt at lower temperature $\left(T_{\mathrm{m}} \sim 143^{\circ} \mathrm{C}\right)$ than those obtained at $100^{\circ} \mathrm{C}$ $\left(T_{\mathrm{m}} \sim 146^{\circ} \mathrm{C}\right)$. The share of fraction melting at $152^{\circ} \mathrm{C}$ is larger in compositions of PLA admixed with $\mathrm{CX}-\mathrm{OH}, \mathrm{CX}-(\mathrm{OH})_{2}$ and $\mathrm{CX}-\mathrm{COOH}$ capable of stronger hydrogen bonding to PLA chains. No solid state endothermic disorder-to-order phase transition of $\alpha^{\prime}$ to $\alpha$ form $[48,52]$ was detected.

At $T=120^{\circ} \mathrm{C}$ crystallization of PLA is slowed down due to the increased dynamics of polymer chains. Small endotherms of cold crystallization (within $110-120^{\circ} \mathrm{C}$ ) were noted for PLA/CX-Vi and PLA/ $\mathrm{CX}-\mathrm{COOMe}$ (Figure 11b), indicating that despite long thermal annealing at $120^{\circ} \mathrm{C}$ they were not completely crystallized. The respective degree of crystallinity is small (e.g. $\sim 8 \%$ for $\Delta H_{\mathrm{cc}}$ and $28 \%$ in total for $\mathrm{PLA} / \mathrm{CX}-\mathrm{COOMe})$. Composites containing $\mathrm{CX}-\mathrm{RCX}-\mathrm{R}$ that form strong $-\mathrm{OH} \cdots \mathrm{O}=\mathrm{C}$ hydrogen bonds with PLA crystallized effectively at this temperature (achieved degree of crystallinity of $\geq 40 \%$ at $t_{1 / 2}$ much shorter than that found for neat PLA). 

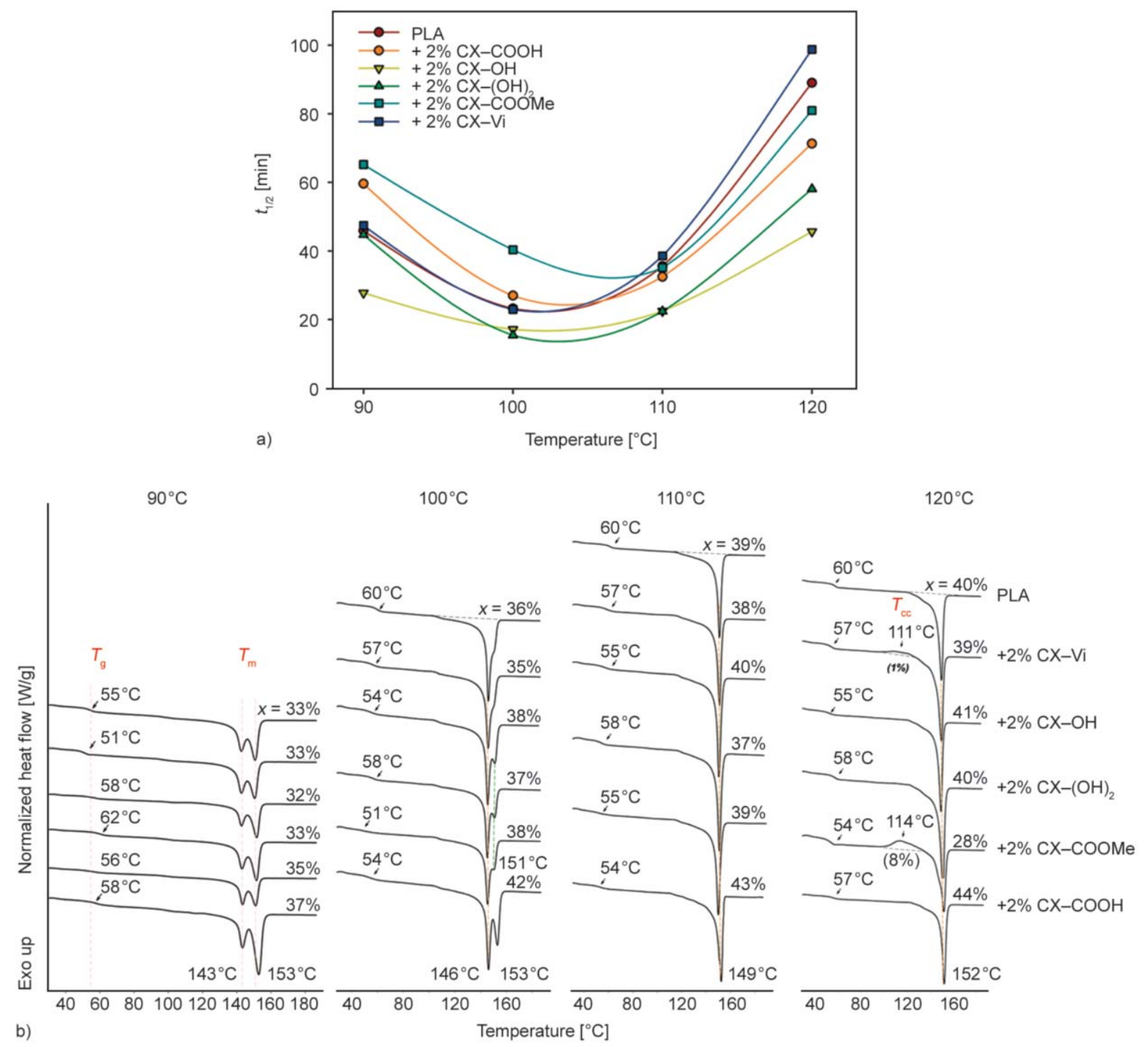

Figure 11. (a) Isothermal crystallization half-times estimated for PLA/CX-R; (b) DSC heating runs $\left(10^{\circ} \mathrm{C} \cdot \mathrm{min}^{-1}\right)$ recorded for samples of PLA $/ 2 \mathrm{wt} \% \mathrm{CX}-\mathrm{R}$ crystallized isothermally at $90,100,110$ and $120^{\circ} \mathrm{C}$.

Interactions between PLA and $\mathrm{CX}-\mathrm{R}(\mathrm{R}=\mathrm{COOH}$, $\mathrm{COOMe}$ and $\mathrm{OH}$ ) were also studied with FTIR in comparison to pure PLA under conditions of isothermal crystallization from melt carried out for one hour after cooling to 100,110 or $120^{\circ} \mathrm{C}$ (procedure I). FTIR spectroscopy is sensitive to the conformation of polymer chains as well as the local molecular environment and crystal packing. The technique is facile and rapid and thus it can be applied for the analysis of PLA crystallization process and structural variations of the formed crystals [49, 5356]. The amount of CX-R $(2 \mathrm{wt} \%)$ is small and FTIR spectra of PLA/CX-R and pure PLA consist of the same characteristic vibration modes. They were converted to their second derivatives in order to resolve more precisely the overlapped bands (Figure 12).
The studied region of $1300-700 \mathrm{~cm}^{-1}$ contains conformation sensitive vibration modes characteristic of the ester backbone of PLA and the crystalline fraction that were assigned (Table 2) following the published data $[49,50,53,55,57,58]$. Isothermal crystallizations at low temperatures $\left(T<100^{\circ} \mathrm{C}\right)$ and cold crystallization caused by accelerated chain motions result typically in the disordered $\alpha^{\prime}$ form whereas tightly packed $\alpha$ crystals are typically obtained at $T \geq 120^{\circ} \mathrm{C}$ [49]. The difference between the chain conformations in $\alpha^{\prime}$ - and $\alpha$-crystals is mainly related to the side groups packing. The band at $\sim 920 \mathrm{~cm}^{-1}$ associated with $\rho\left(\mathrm{CH}_{3}\right)$ vibrations with $v(\mathrm{C}-\mathrm{COO})$ skeletal stretching modes is an indicator of $10_{3}$ helical chain conformations ( $\alpha$ and $\alpha^{\prime}$ crystals). Two other indicative bands are combination of $v(\mathrm{COC})+\rho\left(\mathrm{CH}_{3}\right)$ modes and the stretching $v(\mathrm{C}-\mathrm{COO})[59,60]$. The 


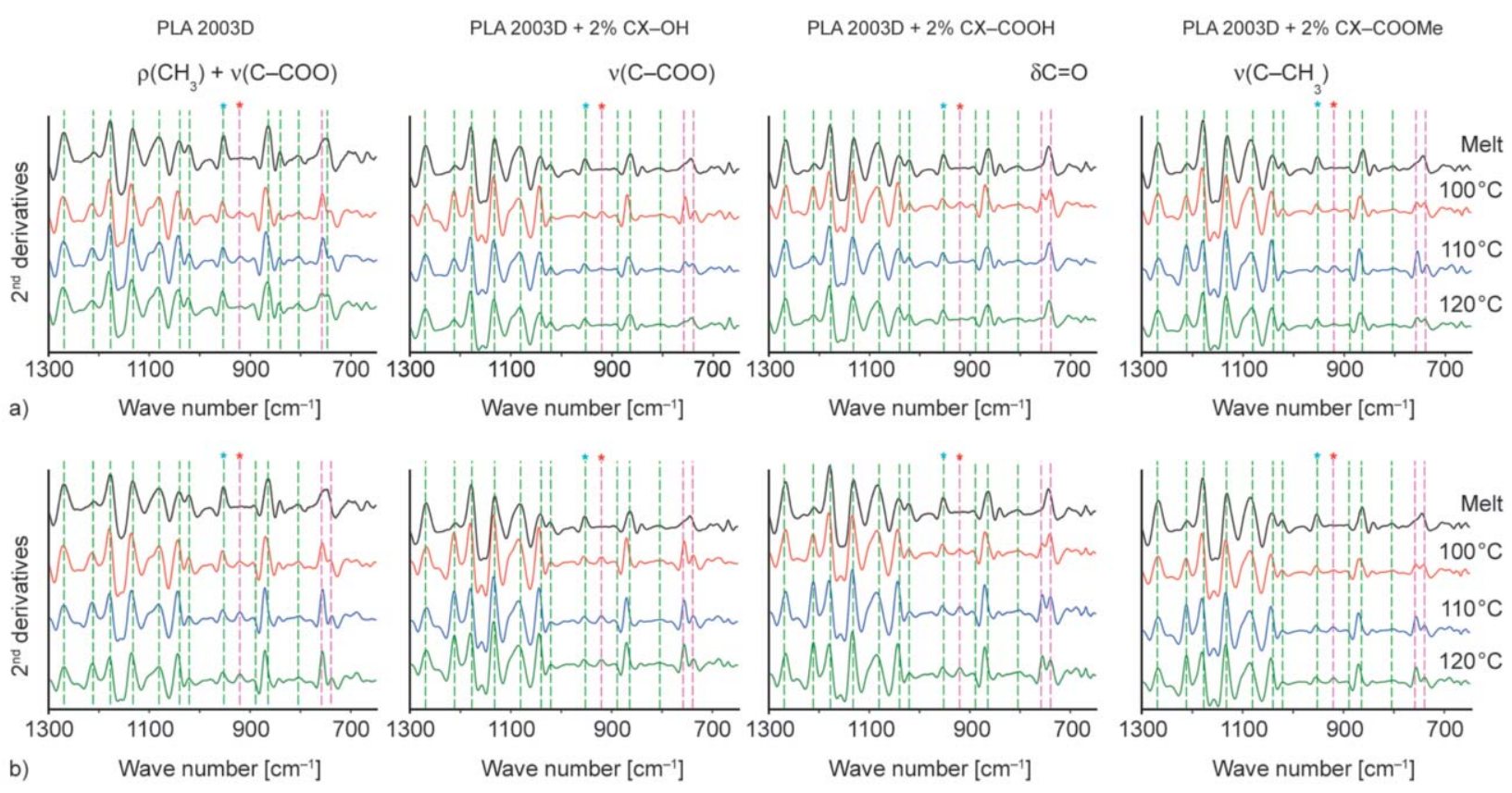

Figure 12. Second derivatives of FTIR spectra of PLA and PLA/CX-R recorded after $1 \mathrm{~h}$ of isothermal crystallization: (a) procedure I; (b) procedure II; $\left[\rho\left(\mathrm{CH}_{3}\right)+v(\mathrm{C}-\mathrm{COO})\right.$ *-amorphous; *- $10_{3}$ conformation mode].

shape of the crystal (curved crystals with edge-on orientation vs crystals with flat-on orientation) also affects the intensity of IR spectral bands [57].

Propensity of the native PLA to crystallize from melt under the applied conditions was most significant at 100 and $110^{\circ} \mathrm{C}$ - in accordance with the published data as well as the presented isothermal crystallization half-times and the post-crystallization melting curves (Figure 11). The spectra recorded after cooling down to the temperature of 100,110 and $120^{\circ} \mathrm{C}$ are very close, which points to a similar degree of chain order. The intensity of vibration bands at 1213 , 1093, 1042 and $757 \mathrm{~cm}^{-1}$ increased and the peaks characteristic of the amorphous fraction $(1022,955$ and $742 \mathrm{~cm}^{-1}$ ) decreased with heating. The position of the skeletal stretching vibration band $\left(922 \mathrm{~cm}^{-1}\right)$ at $100{ }^{\circ} \mathrm{C}$, points to the formation of less regular $\alpha^{\prime}$ crystals. The peak shifts to $920 \mathrm{~cm}^{-1}$ if the crystallization is carried out at $110^{\circ} \mathrm{C}$. However, at $120^{\circ} \mathrm{C}$ no signal indicating $10_{3}$ conformations was found around $920 \mathrm{~cm}^{-1}$, which corroborates with the observed large $t_{1 / 2}$. The vibration bands in the studied region are sharper than those in melt. It was previously explained that the increase of intensity of certain vibration bands should be rather associated with an oriented mesophase and a better packing of macromolecules achieved before the sample crystallization $[50,54,61]$.

Table 2. Assignment of PLA IR vibration bands.

\begin{tabular}{|c|c|c|c|c|c|c|c|}
\hline Vibration band & Amorphous & $\alpha^{\prime}$ & $\alpha$ & Vibration band & Amorphous & $\alpha^{\prime}$ & $\alpha$ \\
\hline & \multicolumn{3}{|c|}{$\begin{array}{c}\text { Wavenumber } \\
{\left[\mathbf{c m}^{-1}\right]}\end{array}$} & \multicolumn{4}{|c|}{$\begin{array}{c}\text { Wavenumber } \\
{\left[\mathrm{cm}^{-1}\right]}\end{array}$} \\
\hline$\delta_{2} \mathrm{CH}$ & 1304 & 1303 & 1303 & $v\left(\mathrm{C}-\mathrm{CH}_{3}\right)$ & $\begin{array}{l}1042 \\
1023\end{array}$ & $\begin{array}{l}1042 \\
1023\end{array}$ & $\begin{array}{l}1042 \\
1023\end{array}$ \\
\hline$\delta \mathrm{CH}+v \mathrm{COC}$ & \multicolumn{3}{|c|}{1270} & $\begin{array}{l}\rho\left(\mathrm{CH}_{3}\right)+v(\mathrm{C}-\mathrm{COO}) \\
\text { amorphous }\end{array}$ & 955 & 955 & 955 \\
\hline$v_{\text {as }}(\mathrm{COC})+\rho_{\mathrm{as}}\left(\mathrm{CH}_{3}\right)$ & $\begin{array}{l}1213 \\
1183\end{array}$ & $\begin{array}{l}1215 \\
1186\end{array}$ & $\begin{array}{l}1222 \\
1213 \\
1202 \\
1180\end{array}$ & $\begin{array}{l}\rho\left(\mathrm{CH}_{3}\right)+v(\mathrm{C}-\mathrm{COO}) \\
\text { crystalline }\end{array}$ & - & 922 & 920 \\
\hline$\rho_{\mathrm{s}}\left(\mathrm{CH}_{3}\right)$ & 1132 & 1134 & $\begin{array}{l}1144 \\
1134\end{array}$ & $v(\mathrm{C}-\mathrm{COO})$ & 864 & 868 & 868 \\
\hline$v_{\mathrm{s}}(\mathrm{COC})$ & 1081 & $\begin{array}{l}1093 \\
1081\end{array}$ & $\begin{array}{l}1093 \\
1081\end{array}$ & $\delta \mathrm{C}=\mathrm{O}$ & & $740-76$ & \\
\hline
\end{tabular}


Changes in the shape of FTIR spectra of PLA/CX-R during direct isothermal crystallizations from the melt suggest a more rapid formation of crystal nuclei that led to an increase of the overall crystallinity of PLA compositions (Figure 12a). CX-OH induced an extensive crystallization of PLA at $100^{\circ} \mathrm{C}$ with the skeletal band of $\rho\left(\mathrm{CH}_{3}\right)+v(\mathrm{C}-\mathrm{COO})$ positioned at $920 \mathrm{~cm}^{-1}$. An outstanding increase of the band at $1213 \mathrm{~cm}^{-1}$ (C-O stretching $\mathrm{E}_{1}$ mode - perpendicular to helix axis [57]) was observed with regard to another $\mathrm{C}-\mathrm{O}$ stretching contribution at $1180 \mathrm{~cm}^{-1}$ (A mode - parallel to the helix axis). It was accompanied with a sharp increase of the $v\left(\mathrm{C}-\mathrm{CH}_{3}\right)$ vibration mode at $1042 \mathrm{~cm}^{-1}$, indicating interactions of adjacent $\mathrm{C}-\mathrm{CH}_{3}$ groups in the crystal unit cell and a decrease of intensity of the amorphous phase band at $955 \mathrm{~cm}^{-1}$. A similar effect was observed before but for enantiomerically pure PLLA and only at $T>$ $110^{\circ} \mathrm{C}[58,62]$. FTIR studies confirmed a slightly slower crystallization of PLA/CX-OH at 110 and $120^{\circ} \mathrm{C}$ (corroborated by the estimated $t_{1 / 2}$ ). Similar (but less pronounced) effects were observed for $\mathrm{CX}-\mathrm{COOH}$. Samples crystallized at $100^{\circ} \mathrm{C}$ were also thermally annealed at $110^{\circ} \mathrm{C}$ and then at $120^{\circ} \mathrm{C}$ (procedure II, Figure 12b). Gradual thermal processing of pre-crystallized samples led to an improvement of the crystal structure. As expected, nuclei formed at $100^{\circ} \mathrm{C}$ acted as templates for the crystal growth at higher temperatures. Intensity of $\mathrm{v}_{\mathrm{as}}(\mathrm{CCO}-\mathrm{O})+$ $\rho_{\text {as }}\left(\mathrm{CH}_{3}\right)\left(1213 \mathrm{~cm}^{-1}\right)$ and $\rho_{\mathrm{s}}\left(\mathrm{CH}_{3}\right)\left(1134 \mathrm{~cm}^{-1}\right)$ was augmented during the annealing. Crystallization of PLA in the presence of CX-COOMe was most rapid at $110^{\circ} \mathrm{C}$, both during thermal annealing carried out according to procedures I and II. The organization of polymer matrix was not much improved on heating at $120^{\circ} \mathrm{C}$, as it was shown also by results presented on Figure 11.

Traces of interactions between the functional groups of CX-R and PLA backbone may be derived from the small differences in $\delta \mathrm{C}=\mathrm{O}$ at $\sim 750 \mathrm{~cm}^{-1}$. In the case of PLA the broad band splits into two peaks (at about 753 and $746 \mathrm{~cm}^{-1}$ ) of intensity ratio dependent on the crystallization temperature, as earlier reported [63]. For $\mathrm{CX}-\mathrm{OH}$ and $\mathrm{CX}-\mathrm{COOMe}$, the ratio of vibration modes is slightly smaller despite much more intensive skeletal bands of $v_{\text {as }}(\mathrm{COC})+\rho_{\text {as }}\left(\mathrm{CH}_{3}\right)\left(1213 \mathrm{~cm}^{-1}\right)$ and $\rho\left(\mathrm{CH}_{3}\right)+v(\mathrm{C}-\mathrm{COO})\left(920 \mathrm{~cm}^{-1}\right)$. The effect was most pronounced for PLA/CX-COOH.

\subsection{Nanomechanical properties}

Depth-sensing indentation (CSM and BASIC methods) was used to evaluate the micro- and nano-scale mechanical properties of amorphous PLA matrices with incorporated additives. Hardness and elastic modulus were derived assuming linear elastic behaviour of the material at the onset of unloading. The extracted data allowed resolving spatially the properties of the heterogeneous nanocomposites, either across the thickness or along the surface. Nanoindentation experiments with moulded and quenched samples were performed at different indentation depths (Figure 13). The change of elastic modulus and hardness of native PLA and PLA/CX-Vi with the indentation depth is typical for viscoelastic polymer materials [64-66]. The effect can be also explained in terms of a surface 'skin'. Larger chain dynamics and lower amount of entanglements at the surface result in changes in properties through sample thickness. A slightly different trend in depth dependence of mechanical properties was noted for CX-R capable of hydrogen bonding with PLA.

Hardness and modulus mapping using the BASIC method allowed for their quantitative determinations with high spatial resolution (Figure 13). Profiles of the local hardness and modulus obtained from the lines of indents on the surface of PLA/CX-R were used. Micromechanical properties were influenced by the mixture composition. It was found that changes of surface stiffness and hardness are uniform for PLA with evenly dispersed $\mathrm{CX}-\mathrm{OH}$. More pronounced local variations of the mechanical properties were observed (in accordance with SEM-EDS) for PLA/ $\mathrm{CX}-\mathrm{COOH}$ [and PLA/CX- $(\mathrm{OH})_{2}$ - not shown]. Changes of surface hardness and elasticity indicate that the accumulated CX-R locally changed PLA properties. It is known that the improvement of mechanical properties of nanocomposites depends on the dispersion of the filler and its interactions with polymer matrix [65]. Inhomogeneous microstructural composition of some PLA/CX-R may be thus responsible for the observed differences in surface hardening. Moreover, the nanoscale properties of semicrystalline polymers can vary due to the presence of amorphous and crystalline domains [67]. Thus, PLA macromolecules linked with nucleating molecules of CX-R can be better organized than the more amorphous part of the sample. 

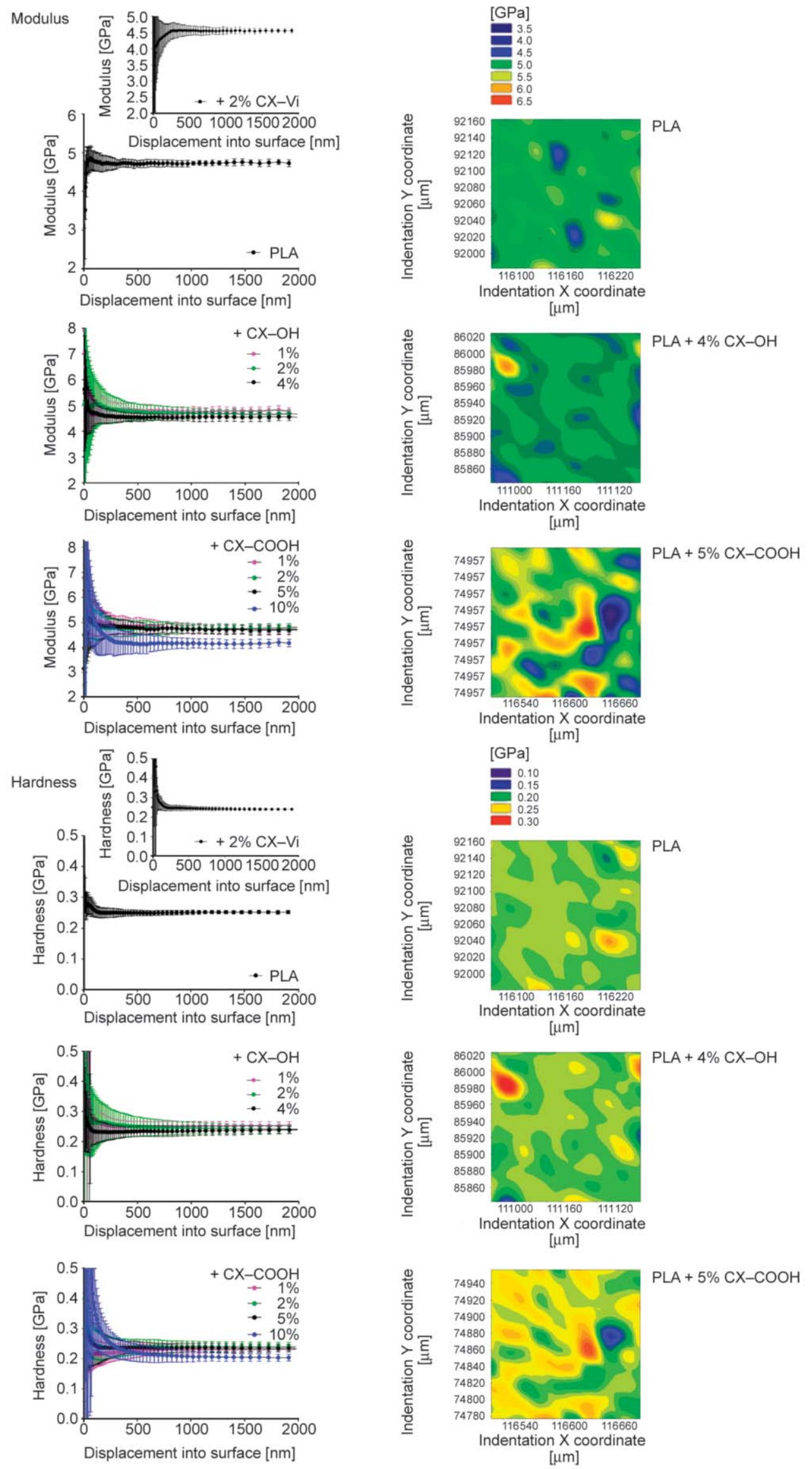

Figure 13. Variation of modulus and hardness with displacement into surface (with exemplary surface maps) of neat PLA and its nanocomposites with $\mathrm{CX}-\mathrm{OH}$ and $\mathrm{CX}-\mathrm{COOH}$ (inserts: $\mathrm{E}$ and $\mathrm{H}$ obtained for PLA admixed with $\mathrm{CX}-\mathrm{Vi}$ at $2 \mathrm{wt} \%)$. 


\section{Conclusions}

Cyclotetrasiloxanes (CX-R) with hydrogen bond accepting/donating functional groups engage in a range of supramolecular interactions with polylactide chains. The nature of those interactions was explored using a combination of complementary analytical methods. Low molecular weight cyclosiloxane compounds were evenly dispersed in the polymer matrix and their presence was clearly reflected in the polymer dielectric response. Distinct relaxation processes associated with different types of hydrogen bonding were observed. It was also found that $\mathrm{CX}-\mathrm{R}$, despite their very low aspect ratio, can work efficiently as nucleating agents for PLA. Formation of characteristic crystal structures was determined by the kind and the amount of the additive. $\mathrm{CX}-\mathrm{OH}$ with hydrogen bond donating hydroxyl groups induced formation of $\alpha$ crystals at temperatures lower than those required for a similar effect with neat PLA, and also lower than those reported for enantiomerically pure PLLA. Samples prepared with CX-COOH of strong hydrogen bond donor/acceptor ability exhibited a specific phase separation at higher loading. Modifications in the long-range chain structure were reflected in variations of the heat flow recorded with DSC and corroborated with changes in the local molecular environment (short-range vibrations) indicated by FTIR.

\section{Acknowledgements}

A. Kowalewska, A.S. Herc, M. Nowacka and J. Bojda thank Polish National Centre of Sciences (NCN) for the financial support within grant No 2016/21/B/ST5/03070.

\section{References}

[1] Castro-Aguirre E., Iñiguez-Franco F., Samsudin H., Fang X., Auras R.: Poly(lactic acid) - Mass production, processing, industrial applications, and end of life. Advanced Drug Delivery Reviews, 107, 333-366 (2016). https://doi.org/10.1016/j.addr.2016.03.010

[2] Di Lorenzo M. L., Androsch R.: Synthesis, structure and properties of poly(lactic acid). Springer, Cham (2018). https://doi.org/10.1007/978-3-319-64230-7

[3] Murariu M., Dubois P.: PLA composites: From production to properties. Advanced Drug Delivery Reviews, 107, 17-46 (2016). https://doi.org/10.1016/j.addr.2016.04.003

[4] Basu A., Nazarkovsky M., Ghadi R., Khan W., Domb A. J.: Poly(lactic acid)-based nanocomposites. Polymers for Advanced Technologies, 28, 919-930 (2017). https://doi.org/10.1002/pat.3985
[5] De Santis P., Kovacs A. J.: Molecular conformation of poly(S-lactic acid). Biopolymers, 6, 299-306 (1968). https://doi.org/10.1002/bip.1968.360060305

[6] Wasanasuk K., Tashiro K., Hanesaka M., Ohhara T., Kurihara K., Kuroki R., Tamada T., Ozeki T., Kanamoto T.: Crystal structure analysis of Poly(L-lactic acid) $\alpha$ form on the basis of the 2-dimensional wide-angle synchrotron X-ray and neutron diffraction measurements. Macromolecules, 44, 6441-6452 (2011).

https://doi.org/10.1021/ma2006624

[7] Müller A. J., Ávila M., Saenz G., Salazar J.: Crystallization of PLA-based materials. in 'Poly(lactic acid) science and technology: Processing, properties, additives and applications' (eds.: Jiménez A., Peltzer M., Ruseckaite R.) The Royal Society of Chemistry, Cambridge, RSC Polymer Chemistry Series, 12, 66-98 (2015).

https://doi.org/10.1039/9781782624806-00066

[8] Saeidlou S., Huneault M. A., Li H., Park C. B.: Poly (lactic acid) crystallization. Progress in Polymer Science, 37, 1657-1677 (2012).

https://doi.org/10.1016/j.progpolymsci.2012.07.005

[9] Xu J-Z., Zhong G-J., Hsiao B. S., Fu Q., Li Z-M.: Lowdimensional carbonaceous nanofiller induced polymer crystallization. Progress in Polymer Science, 39, 555593 (2014).

https://doi.org/10.1016/j.progpolymsci.2013.06.005

[10] Brzeziński M., Biela T.: Polylactide nanocomposites with functionalized carbon nanotubes and their stereocomplexes: A focused review. Materials Letters, 121, 244-250 (2014).

https://doi.org/10.1016/j.matlet.2014.01.159

[11] Xu H., Adolfsson K. H., Xie L., Hassanzadeh S., Pettersson T., Hakkarainen M.: Zero-dimensional and highly oxygenated graphene oxide for multifunctional poly(lactic acid) bionanocomposites. ACS Sustainable Chemistry and Engineering, 4, 5618-5631 (2016). https://doi.org/10.1021/acssuschemeng.6b01524

[12] Bayer I. S.: Thermomechanical properties of polylactic acid-graphene composites: A state-of-the-art review for biomedical applications. Materials, 10, 748/1-748/33 (2017).

https://doi.org/10.3390/ma10070748

[13] Ege D., Kamali A. R., Boccaccini A. R.: Graphene oxide/ polymer-based biomaterials. Advanced Engineering Materials, 19, 1700627/1-1700627/22 (2017).

https://doi.org/10.1002/adem.201700627

[14] Lai W-C.: Thermal behavior and crystal structure of poly(L-lactic acid) with 1,3:2,4-dibenzylidene- $d$-sorbitol. Journal of Physical Chemistry B, 115, 1102911037 (2011). https://doi.org/10.1021/jp2037312

[15] Li C., Luo S., Wang J., Wu H., Guo S., Zhang X.: Conformational regulation and crystalline manipulation of PLLA through a self-assembly nucleator. Biomacromolecules, 18, 1440-1448 (2017). https://doi.org/10.1021/acs.biomac.7b00367 
[16] Feng Y., Ma P., Xu P., Wang R., Dong W., Chen M., Joziasse C.: The crystallization behavior of poly(lactic acid) with different types of nucleating agents. International Journal of Biological Macromolecules, 106, 955 962 (2018).

https://doi.org/10.1016/j.ijbiomac.2017.08.095

[17] Nam J. Y., Okamoto M., Okamoto H., Nakano M., Usuki A., Matsuda M.: Morphology and crystallization kinetics in a mixture of low-molecular weight aliphatic amide and polylactide. Polymer, 47, 1340-1347 (2006).

https://doi.org/10.1016/j.polymer.2005.12.066

[18] Bai H., Huang C., Xiu H., Zhang Q., Deng H., Wang K., Chen F., Fu Q.: Significantly improving oxygen barrier properties of polylactide via constructing parallelaligned shish-kebab-like crystals with well-interlocked boundaries. Biomacromolecules, 15, 1507-1514 (2014). https://doi.org/10.1021/bm500167u

[19] Xie Q., Han L., Shan G., Bao Y., Pan P.: Polymorphic crystalline structure and crystal morphology of enantiomeric poly(lactic acid) blends tailored by a self-assemblable aryl amide nucleator. ACS Sustainable Chemistry and Engineering, 4, 2680-2688 (2016). https://doi.org/10.1021/acssuschemeng.6b00191

[20] Mierzwa M., Floudas G., Dorgan J., Knauss D., Wegner J.: Local and global dynamics of polylactides.: A dielectric spectroscopy study. Journal of Non-Crystalline Solids, 307-310, 296-303 (2002).

https://doi.org/10.1016/S0022-3093(02)01480-1

[21] Brás A. R., Viciosa M. T., Wang Y., Dionísio M., Mano J. F.: Crystallization of poly(L-lactic acid) probed with dielectric relaxation spectroscopy. Macromolecules, 39, 6513-6520 (2006).

https://doi.org/10.1021/ma061148r

[22] Brás A. R., Malik P., Dionísio M., Mano J. F.: Influence of crystallinity in molecular motions of poly(L-lactic acid) investigated by dielectric relaxation spectroscopy. Macromolecules, 41, 6419-6430 (2008).

https://oi.org/10.1021/ma800842a

[23] Zhang Y., Li J., Zhang Z., Li H., Meng Y., Jiang S.: Dynamical behaviors of polylactide crystallization. Journal of Polymer Research, 26, 72/1-72/9 (2019).

https://doi.org/10.1007/s10965-019-1698-4

[24] Leng J., Kang N., Wang D-Y., Falkenhagen J., Thünemann A. F., Schönhals A.: Structure-property relationships of nanocomposites based on polylactide and layered double hydroxides - Comparison of MgAl and NiAl LDH as nanofiller. Macromolecular Chemistry and Physics, 218, 1700232/1-1700232/12 (2017). https://doi.org/10.1002/macp.201700232

[25] Pluta M., Jeszka J. K., Boiteux G.: Polylactide/montmorillonite nanocomposites: Structure, dielectric, viscoelastic and thermal properties. European Polymer Journal, 43, 2819-2835 (2007).

https://doi.org/10.1016/j.eurpolymj.2007.04.009
[26] Klonos P., Kripotou S., Kyritsis A., Papageorgiou G. Z., Bikiaris D., Gournis D., Pissis P.: Glass transition and segmental dynamics in poly(L-lactic acid)/graphene oxide nanocomposites. Thermochimica Acta, 617, 4453 (2015).

https://doi.org/10.1016/j.tca.2015.08.020

[27] Yousefzade O., Valenti S., Puiggalí J., Garmabi H., Macovez R.: Segmental relaxation and partial crystallization of chain-extended poly(L-lactic acid) reinforced with carboxylated carbon nanotube. Journal of Polymer Science Part B, Polymer Physics, 57, 222-233 (2018). https://doi.org/10.1002/polb.24774

[28] Chiulan I., Frone A. N., Brandabur C., Panaitescu D. M.: Recent advances in 3D printing of aliphatic polyesters. Bioengineering, 5, 2/1-2/18 (2018). https://doi.org/10.3390/bioengineering5010002

[29] Baran E. H., Erbil H. Y.: Surface modification of 3D printed PLA objects by fused deposition modeling: A review. Colloids Interfaces, 3, 43/1-43/25 (2019).

https://doi.org/10.3390/colloids3020043

[30] Coppola B., Cappetti N., Di Maio L., Scarfato P., Incarnato L.: 3D printing of PLA/clay nanocomposites: Influence of printing temperature on printed samples properties. Materials, 11, 1947/1-1947/17 (2018).

https://doi.org/10.3390/ma11101947

[31] Kaygusuz B., Özerinç S.: Improving the ductility of polylactic acid parts produced by fused deposition modeling through polyhydroxyalkanoate additions. Journal of Applied Polymer Science, 136, 48154/1-48154/8 (2019).

https://doi.org/10.1002/APP.48154

[32] Kowalewska A., Nowacka M., Tracz A., Makowski T.: Supramolecular self-assembly of linear oligosilsesquioxanes on mica - AFM surface imaging and hydrophilicity studies. Soft Matter, 11, 4818-4829 (2015).

https://doi.org/10.1039/C5SM00787A

[33] Nowacka M., Kowalewska A., Makowski T.: Nanostructured surfaces by supramolecular self-assembly of linear oligosilsesquioxanes with biocompatible side groups. Beilstein Journal of Nanotechnology, 6, 23772387 (2015).

https://doi.org/10.3762/bjnano.6.244

[34] Armarego W. L. F., Chai C. L. L.: Purification of laboratory chemicals. Butterworth-Heinemann, Bodmin (2003).

https://doi.org/10.1016/B978-0-7506-7571-0.X5000-5

[35] Oliver W. C., Pharr M. G.: An improved technique for determining hardness and elastic modulus using load and displacement sensing indentation experiments. Journal of Materials Research, 7, 1564-1583 (1992). https://doi.org/10.1557/JMR.1992.1564

[36] Li X., Bhushan B.: A review of nanoindentation continuous stiffness measurement technique and its applications. Materials Characterization, 48, 11-36 (2002). https://doi.org/10.1016/S1044-5803(02)00192-4 
[37] Pelletier E., Harrod J. F.: Cyclosiloxanes as frameworks for multimetallic compounds. 3. Proton NMR spectra of some substituted methylcyclosiloxanes. Organometallics, 3, 1070-1075 (1984).

https://doi.org/10.1021/om00085a018

[38] Makarova N. N., Petrova I. M., Petrovskii P. V., Kaznacheev A. V., Volkova L. M., Shcherbina M. A., Bessonova N. P., Chvalun S. N., Godovskii Yu. K.: Synthesis of new stereoregular 2,4,6,8-tetraphenylcyclotetrasiloxanes with mesogenic groups and the influence of spatial isomerism on the phase state of individual isomers and their mixtures. Russian Chemical Bulletin, 53, 1983-1992 (2004).

https://doi.org/10.1007/s11172-005-0059-0

[39] Ryuichi I., Yuriko K., Yusuke K.: Cyclic tetrasiloxanetetraols: Formation, isolation, and characterization. Chemistry Letters, 38, 364-365 (2009). https://doi.org/10.1246/cl.2009.364

[40] Pozdnyakova Y. A., Korlyukov A. A., Kononova E. G., Lyssenko K. A., Peregudov A. S., Shchegolikhina O. I.: Cyclotetrasiloxanetetrols with methyl groups at silicon: Isomers all-cis- and cis-trans-cis-[MeSi(O)OH $]_{4}$. Inorganic Chemistry, 49, 572-577 (2010). https://doi.org/10.1021/ic9017079

[41] Deshmukh M. S., Vijayakanth T., Boomishankar R.: Stereochemically distinct cyclotetrasiloxanes containing 3-pyridyl moieties and their functional coordination polymers. Inorganic Chemistry, 55, 3098-3104 (2016). https://doi.org/10.1021/acs.inorgchem.6b00001

[42] ASTM D1746-03: Standard test method for transparency of plastic sheeting (2015).

[43] Havriliak S., Negami S.: A complex plane representation of dielectric and mechanical relaxation processes in some polymers. Polymer, 8, 161-210 (1967). https://doi.org/10.1016/0032-3861(67)90021-3

[44] Fischer E. W., Sterzel H. J., Wegner G.: Investigation of the structure of solution grown crystals of lactide copolymers by means of chemical reactions. KolloidZeitschrift und Zeitschrift für Polymere, 251, 980-990 (1973). https://doi.org/10.1007/BF01498927

[45] Kikkawa Y., Abe H., Fujita M., Iwata T., Inoue Y., Doi Y.: Crystal growth in poly(L-lactide) thin film revealed by in situ atomic force microscopy. Macromolecular Chemistry and Physics, 204, 1822-1831 (2003). https://doi.org/10.1002/macp.200350044

[46] Zhao L-S., Cai Y-H.: Investigating the physical properties of poly(L-lactic acid) modified using an aromatics succinic dihydrazide derivative. Polymer Science, Series A, 6, 777-787 (2018). https://doi.org/10.1134/S0965545X18070088

[47] Tsui H.: Poly(lactic acid) stereocomplexes: A decade of progress. Advanced Drug Delivery Reviews, 107, 97 135 (2016).

https://doi.org/10.1016/j.addr.2016.04.017
[48] Zhang J., Tashiro K., Tsuji H., Domb A. J.: Disorderto-order phase transition and multiple melting behavior of poly(L-lactide) investigated by simultaneous measurements of WAXD and DSC. Macromolecules, 41, 1352-1357 (2008).

https://doi.org/10.1021/ma0706071

[49] Pan P., Zhu B., Kai W., Dong T., Inoue Y.: Polymorphic transition in disordered poly(L-lactide) crystals induced by annealing at elevated temperatures. Macromolecules, 41, 4296-4304 (2008).

https://doi.org/10.1021/ma800343g

[50] Wasanasuk K., Tashiro K.: Structural regularization in the crystallization process from the glass or melt of poly(L-lactic acid) viewed from the temperature-dependent and time-resolved measurements of FTIR and wide-angle/small-angle X-ray scatterings. Macromolecules, 44, 9650-9660 (2011).

https://doi.org/10.1021/ma2017666

[51] Gracia-Fernández C., Gómez-Barreiro S., López-Beceiro J., Naya S., Artiaga R.: New approach to the double melting peak of poly(L-lactic acid) observed by DSC. Journal of Materials Research, 27, 1379-1382 (2012). https://doi.org/10.1557/jmr.2012.57

[52] Zhang J., Duan Y., Sato H., Tsuji H., Noda I., Yan S., Ozaki Y.: Crystal modifications and thermal behavior of poly(L-lactic acid) revealed by infrared spectroscopy. Macromolecules, 38, 8012-8021 (2005). https://doi.org/10.1021/ma051232r

[53] Kister G., Cassanas G., Vert M.: Effects of morphology, conformation and configuration on the IR and Raman spectra of various poly(lactic acid)s. Polymer, 39, 267273 (1998). https://doi.org/10.1016/S0032-3861(97)00229-2

[54] Meaurio E., Zuza E., López-Rodríguez N., Sarasua J. R.: Conformational behavior of poly(L-lactide) studied by infrared spectroscopy. Journal od Physical Chemistry B, 110, 5790-5800 (2006). https://doi.org/10.1021/jp055203u

[55] Pan P., Yang J., Shan G., Bao Y., Weng Z., Cao A., Yazawa K., Inoue Y.: Temperature-variable FTIR and solid-state ${ }^{13} \mathrm{C}$ NMR investigations on crystalline structure and molecular dynamics of polymorphic poly(Llactide) and poly(L-lactide)/poly(D-lactide) stereocomplex. Macromolecules, 45, 189-197 (2012). https://doi.org/10.1021/ma201906a

[56] Kang S., Hsu S. L., Stidham H. D., Smith P. B., Leugers M. A., Yang X.: A spectroscopic analysis of poly(lactic acid) structure. Macromolecules, 34, 4542-4548 (2001). https://doi.org/10.1021/ma0016026

[57] Meaurio E., López-Rodróguez N., Sarasua J. R.: Infrared spectrum of poly(L-lactide): Application to crystallinity studies. Macromolecules, 39, 9291-9301 (2006). https://doi.org/10.1021/ma061890r 
[58] Pan P., Zhu B., Kai W., Dong T., Inoue Y.: Effect of crystallization temperature on crystal modifications and crystallization kinetics of poly(L-lactide). Journal of Applied Polymer Science, 107, 54-62 (2008). https://doi.org/10.1002/app.27102

[59] Zhang J., Tsuji H., Noda I., Ozaki Y.: Weak intermolecular interactions during the melt crystallization of poly (L-lactide) investigated by two-dimensional infrared correlation spectroscopy. Journal of Physical Chemistry B, 108, 11514-11520 (2004). https://doi.org/10.1021/jp048308q

[60] Lan Q., Yu J., Zhang J., He J.: Nucleation enhancement in stereodefective poly(L-lactide) by free volume expansion resulting from low-temperature pressure $\mathrm{CO}_{2}$ preconditioning. Polymers, 10, 120/1-120/12 (2018). https://doi.org/10.3390/polym10020120

[61] Xue B., Xie L., Zhang J.: Detailed molecular movements during poly(L-lactic acid) cold-crystallization investigated by FTIR spectroscopy combined with twodimensional correlation analysis. RSC Advances, 7, 47017-47028 (2017). https://doi.org/10.1039/c7ra08921j

[62] Pan P., Liang Z., Zhu B., Dong T., Inoue Y.: Blending effects on polymorphic crystallization of poly(L-lactide). Macromolecules, 42, 3374-3380 (2009).

https://doi.org/10.1021/ma8024943
[63] Vasanthan N., Ly O.: Effect of microstructure on hydrolytic degradation studies of poly (L-lactic acid) by FTIR spectroscopy and differential scanning calorimetry. Polymer Degradation and Stability, 94, 1364-1372 (2009). https://doi.org/10.1016/j.polymdegradstab.2009.05.015

[64] Beyaoui M., Mazeran P-E., Arvieu M-F., Bigerelle M., Guigon M.: Analysis of nanoindentation curves in the case of bulk amorphous polymers. International Journal of Materials Research, 100, 943-949 (2009). https://doi.org/10.3139/146.110137

[65] Díez-Pascual A. M., Gómez-Fatou M. A., Ania F., Flores A.: Nanoindentation in polymer nanocomposites. Progress in Materials Science, 67, 1-94 (2015). https://doi.org/10.1016/j.pmatsci.2014.06.002

[66] Shirazi R. N., Rochev Y., McHugh P.: Nanoindentation of solvent-cast and compression-moulded poly(lacticco-glycolic acid) to determine elastic modulus and hardness. Polymer Testing, 50, 111-118 (2016). https://doi.org/10.1016/j.polymertesting.2016.01.009

[67] Voyiadjis G. Z., Samadi-Dooki A., Malekmotiei L.: Nanoindentation of high performance semicrystalline polymers: A case study on PEEK. Polymer Testing, 61, 57-64 (2017). https://doi.org/10.1016/j.polymertesting.2017.05.005 